INTERNATIONAL

FOOD POLICY

RESEARCH

INSTITUTE

IFPRI

IFPRI Discussion Paper 01507

February 2016

\title{
Determinants of Chemical Fertilizer Use in Nepal \\ Insights Based on Price Responsiveness and Income Effects
}

Hiroyuki Takeshima

Rajendra Prasad Adhikari

Basu Dev Kaphle

Sabnam Shivakoti

Anjani Kumar

Development Strategy and Governance Division 


\section{INTERNATIONAL FOOD POLICY RESEARCH INSTITUTE}

The International Food Policy Research Institute (IFPRI), established in 1975, provides evidence-based policy solutions to sustainably end hunger and malnutrition and reduce poverty. The Institute conducts research, communicates results, optimizes partnerships, and builds capacity to ensure sustainable food production, promote healthy food systems, improve markets and trade, transform agriculture, build resilience, and strengthen institutions and governance. Gender is considered in all of the Institute's work. IFPRI collaborates with partners around the world, including development implementers, public institutions, the private sector, and farmers' organizations, to ensure that local, national, regional, and global food policies are based on evidence. IFPRI is a member of the CGIAR Consortium.

\section{AUTHORS}

Hiroyuki Takeshima (h.takeshima@cgiar.org) is a research fellow in the Development Strategy and Governance Division of the International Food Policy Research Institute (IFPRI), Washington, DC.

Rajendra Prasad Adhikari is joint secretary of the Policy and International Cooperation and Coordination Division of the Nepal Ministry of Agriculture Development, Kathmandu, and a research fellow in Value Chain Management, University of Tasmania, Hobart, Australia.

Basu Dev Kaphle is a senior agricultural economist in the Policy and International Cooperation and Coordination Division of the Nepal Ministry of Agriculture Development, Kathmandu.

Sabnam Shivakoti is a senior agriculture officer in the Policy and International Cooperation and Coordination Division of the Nepal Ministry of Agriculture Development, Kathmandu.

Anjani Kumar is a research fellow in the South Asia Office of IFPRI, New Delhi.

\footnotetext{
Notices

1. IFPRI Discussion Papers contain preliminary material and research results and are circulated in order to stimulate discussion and critical comment. They have not been subject to a formal external review via IFPRI's Publications Review Committee. Any opinions stated herein are those of the author(s) and are not necessarily representative of or endorsed by the International Food Policy Research Institute.

2. The boundaries and names shown and the designations used on the map(s) herein do not imply official endorsement or acceptance by the International Food Policy Research Institute (IFPRI) or its partners and contributors.

Copyright 2016 International Food Policy Research Institute. All rights reserved. Sections of this material may be reproduced for personal and not-for-profit use without the express written permission of but with acknowledgment to IFPRI. To reproduce the material contained herein for profit or commercial use requires express written permission. To obtain permission, contact ifpri-copyright@cgiar.org.
} 


\section{Contents}

Abstract $\quad$ V

Acknowledgments $\quad$ vi

1. Introduction 1

2. Fertilizer Policies in Nepal 3

3. Key Patterns of Fertilizer Use in Nepal $\quad 4$

4. Price Responses and Marginal Value Products of Chemical Fertilizer Use: Empirical $\begin{array}{ll}\text { Methods } & 16\end{array}$

5. Demand for Inorganic Fertilizer: Empirical Results 24

6. Summary and Conclusion 33

Appendix: Calculation of Nutrient Quantities (Inorganic and Organic)—Nitrogen, Phosphorous, and Potassium 35

$\begin{array}{ll}\text { References } & 36\end{array}$ 


\section{Tables}

3.1 Nitrogen use in mountainous/hilly parts of the world ${ }^{\text {a }} \quad 5$

3.2 Total inorganic fertilizer use (1,000 metric tons)

3.3 Use of inorganic fertilizer at farm household level $\quad 7$

3.4 Inorganic fertilizer use (kilograms/hectare of cultivated area, annual)

3.5 Estimated nitrogen, phosphate, and potassium use (kilograms per farm household per year) 8

3.6 Urea price by region $\quad 10$

$\begin{array}{ll}3.7 \text { DAP price by region } & 10\end{array}$

3.8 Ratio of households using manure only to households using chemical fertilizer, by crop 12

3.9 Shares of chemical fertilizer obtained from major sources by fertilizer-using households in each $\begin{array}{ll}\text { agroecological belt } & 13\end{array}$

3.10 Percentage of fertilizer users who could use desired amount of fertilizer 14

3.11 Farm households obtaining credit and average credit amount by source 15

3.12 Farm households obtaining credit for different purposes in $2010 \quad 15$

3.13 Percentage of farm households obtaining credit 15

4.1 Key Nepali Agriculture Research Stations used in the model 17

4.2 Descriptive statistics (all years combined) 19

4.3 Subgroups of farm households defined for assessing returns to chemical fertilizer use (among farm households using chemical fertilizer)

5.1 Determinants of chemical fertilizer use, pseudo-panel, correlated random-effects Tobit (marginal effects evaluated at the means of covariates)

5.2 Average partial price response of fertilizer demand (change in kilograms of fertilizer demand per farm household in response to a one-unit increase in real price)

5.3 Income effects of marginal adoption of chemical fertilizer

5.4 Balancing properties under generalized propensity score matching

5.5 Balancing properties of propensity score matching for marginal users of fertilizer (using chemical fertilizer nutrients of not more than 20 kilograms per year)

A.1 Estimated nutrient composition of inorganic fertilizer used in the study 35

A.2 Estimated manure nutrients sourced from different types of livestock 35

\section{Figures}

3.1 Significant relationship between differences in chemical fertilizer intensity and farm size in the

Terai and in the Hills excluding the central region

3.2 Major crops for which inorganic fertilizer is used, by agroecological belt, year 11

4.1 Locations of Agriculture Research Stations and major universities with breeding activities 17

5.1 Small-size, low-asset owner $\quad 28$

$\begin{array}{ll}5.2 \text { Small-size, high-asset owner } & 29\end{array}$

5.3 Medium-to-large-size, low-asset owner $\quad 30$

5.4 Medium-to-large-size, high-asset owner 30 


\begin{abstract}
Although overall chemical fertilizer use has grown steadily in Nepal in the past two decades, much of that growth has occurred in the Terai agroecological belt while use has stagnated in the Hills and the Mountains regions. Differences in chemical fertilizer use intensity between the Terai and the latter regions are typically pronounced among medium-to-large-size farmers. Using three rounds of the Nepal Living Standards Survey as well as secondary data, we examine the determinants of inorganic fertilizer (urea and DAP) use, as well as the marginal income returns from fertilizer use at the farm-household level. Similarities in soil and climate between farm locale and Agriculture Research Station locale seem to increase demand for fertilizer - even after controlling for distance to those stations. Most important, demand for chemical fertilizer is affected by the real fertilizer price (particularly since the 2003 NLSS survey), but the price response is relatively weaker in the Hills and Mountains, suggesting that returns to fertilizer may be generally low in those regions, and that reducing fertilizer price through subsidies on fertilizer or transportation may not substantially increase fertilizer use. This is confirmed by assessment of the returns to chemical fertilizer use estimated through generalized propensity score matching and ordinary propensity score matching. The findings cast doubt on the effectiveness of fertilizer subsidies as an instrument for stimulating chemical fertilizer use in Nepal, particularly among medium-to-large-scale farmers in the Hills, and point toward alternative measures like increased research and development into technologies that raise overall returns to chemical fertilizer.
\end{abstract}

\title{
Keywords: chemical fertilizer, Nepal Living Standards Survey, pseudo-panel, Tobit model, generalized propensity score, Nepal
}




\section{ACKNOWLEDGMENTS}

We thank the United States Agency for International Development for providing funding for this study through the Policy Reform Initiative Project. We are grateful for the constructive comments received from the participants of the Stakeholder Consultation Meeting held September 2, 2015, in Kathmandu. We also thank Madhab Karkee and Deva Bhakta Shakya for overall guidance and facilitation. Views expressed in this paper are those of the authors and are not necessarily representative of or endorsed by the government of Nepal, the International Food Policy Research Institute, or the United States Agency for International Development. The authors are responsible for all remaining errors. 


\section{INTRODUCTION}

The increased use of inorganic fertilizer is considered an important process of agricultural transformation. Inorganic fertilizer is often considered an important land-saving input, allowing farmers to increase the returns from land, one of the scarce resources they own. Although use of inorganic fertilizer has increased in Nepal in the past few decades, as is described in this paper, its overall intensity of use lags behind that of many other Asian countries, when measured with respect to fertilizer use per farm household or cultivated area. In particular, the slow increase is due to stagnant growth in Nepal's Hills and Mountains agroecological zones. This low usage may be partly due to insufficient demand, as a result of, among other things, the shortage of fertilizer-responsive varieties that suit Nepali production environments, limited access to irrigation facilities, or limited market access aggravated by highly rugged terrain in many parts of the country. Added to this, the relatively mountainous landscape of Nepal suggests that the country may follow the path of other similarly mountainous countries in the world, many of which rely more on organic fertilizer such as manure than on inorganic chemical fertilizer.

\section{Rationale of the Study}

Nepal's government is concerned about the seemingly high prices and questionable quality of chemical fertilizer in the country. However, the price of chemical fertilizer must be compared against crop prices, as they sometimes move together. A second concern of the Nepali government is the lower price of fertilizer in India, which shares a largely unregulated, open border with Nepal. Indian fertilizer may be associated with unknown quality but may also lower fertilizer prices in Nepal. It is also unclear how price itself affects chemical fertilizer use. If the response of chemical fertilizer use to price is limited, price policies may have a limited effect on use. If the initial use of chemical fertilizer is low and price responsiveness is also low, the cost savings from chemical fertilizer use realized through cheaper chemical fertilizer prices is also limited. Similarly, it is not clear why the demand for and sale of chemical fertilizer supplied through private, informal channels remain high despite the perceptions of such fertilizer's poor quality. Overall, a substantial knowledge gap exists regarding demand for chemical fertilizer in Nepal, which complicates the assessment of policy impacts. Therefore, empirical evidence based on a nationally representative sample of farm households is needed to assess the overall impact of fertilizer policies at the national level.

\section{Objectives}

The objective of this study is to provide empirical evidence based on a household-level survey; specifically, we empirically identify the determinants of the quantities of chemical fertilizer farmers use. We attempt to provide evidence indicating that economic returns from chemical nutrients may explain important, though not all, variations in chemical fertilizer use among regions in Nepal. An important policy implication is that, if the policy goal is to raise the use of inorganic fertilizer, employing subsidies to lower fertilizer prices may prove insufficient unless returns to fertilizer are raised, particularly in the Hills and the Mountains. The empirical results provide some insights into possible policy options.

In addition, the paper provides a conceptual model of how farmers might respond to uncertainty in fertilizer quality. It suggests that the general increase in fertilizer use, particularly in the Terai, is inconsistent with the hypothesis that quality is a major constraint to fertilizer use.

\section{Scope and Limitation}

Using a nationally representative survey, the scope of this study is to obtain the large picture, by comparing the agroecological belts (for example, the Terai versus the Hills) or farm households with different production scales (for example, small-scale farmers versus medium-to-large-scale farmers, or 
low-asset-holding farmers versus high-asset-holding farmers). Due to data limitations, the paper does not address more micro-level knowledge gaps (for example, crop-specific productivity effects of chemical fertilizer, the relationship with plot-level soil characteristics, and so forth), levels of fertilizer quality and their productivity effects, or the environmental effects of chemical fertilizer use.

\section{Primary Data Used}

Much of our analysis relies on data from the Nepal Living Standards Survey (NLSS). That survey was conducted in 1995, 2003, and 2010 by Nepal's Central Bureau of Statistics. NLSS data were collected through multistage stratified random sampling methods in each round. Specifically, six strata were defined across Nepal that consist of urban and rural areas in each of the three agroecological belts (Terai, Hills, and Mountains), and enumeration areas were randomly selected from each strata. ${ }^{1}$ In the NLSS 1995, 275 wards were used as enumeration areas, from which 3,388 households were sampled. In the NLSS 2003, 4,008 cross-section samples were randomly selected from 800 enumeration areas, and 1,232 panel samples were randomly selected from the NLSS 1995. In the NLSS 2010, 5,988 cross-section samples were randomly selected from 500 enumeration areas redefined from the 800 enumeration areas in the NLSS 2003, and 1,032 panel samples were randomly selected from the NLSS 2003. Within each enumeration area, households were randomly selected for the interview (Nepal, Central Bureau of Statistics 1996, 2004, 2011a).

\footnotetext{
${ }^{1}$ For the NLSS 1995, only the Hills region was further stratified into urban and rural.
} 


\section{FERTILIZER POLICIES IN NEPAL}

Chemical fertilizer was introduced in Nepal during the 1950s. Formal importation and distribution of fertilizer started with the establishment of the Agriculture Input Corporation (AIC) under the then Ministry of Agriculture in 1966. AIC, as a public-sector enterprise, was fully responsible for the import and distribution of chemical fertilizers in Nepal, especially those from India. After a few years, AIC also started importing fertilizer from the international market. With the introduction of AIC into the fertilizer business, demand for and use of fertilizer increased gradually.

With the aim of increasing food production by encouraging farmers to use chemical fertilizer, the government introduced fertilizer subsidies in 1973-1974 (APROSC 1995). The subsidy policy included both a price subsidy on fertilizer throughout the country and a transport subsidy for selected Hills and mid-Hills districts (APROSC 1995). The transport subsidy applied to costs incurred while transporting fertilizer from the Terai region to the Hills. Fertilizer prices gradually rose over time in international markets, and AIC began operating at a loss, becoming unable to import and distribute fertilizer as before.

In-country demand for chemical fertilizer as well as the price of fertilizer on the international market increased toward the mid-1990s, and the subsidy became a huge financial burden on the government. As a result, in 1997 the government decided to deregulate the fertilizer trade, removing the subsidy on fertilizer and allowing the private sector to import and distribute it. Initially, the subsidy was phased out for diammonium phosphate (DAP) and muriate of potash (MoP); the subsidy for urea was phased out later. After November 1999 no subsidies remained.

After deregulation, the AIC was dissolved and in its place two companies were formed: the Agriculture Inputs Company Limited, responsible for the fertilizer business, and the National Seed Company Limited, responsible for the crop seed business. Thus, deregulation removed the AIC's monopoly in the fertilizer trade and provided opportunities for the private sector to participate.

Furthermore, in 2002, the National Fertilizer Policy (NFP) was formulated. The NFP aimed to (1) provide conditions (policy and infrastructure management) for increased use of fertilizer, and (2) promote an integrated plant nutrient management system (IPNS) for the efficient and balanced use of fertilizers. Under the NFP, policy coverage was expanded to three types of fertilizer-organic, chemical, and microbial. Promotion of the IPNS under the NFP reflected to some degree a shift away from the intensification of chemical fertilizer use to minimizing environmental degradation, even though the economic rationale for that was not clear. The NFP continued to pursue deregulation by treating equally private and cooperative firms involved in the fertilizer business, and by the government's limiting the use of subsidy to the aforementioned transport subsidies. The NFP continued to maintain a concern about fertilizer prices, and it promoted the provision of a buffer stock to prevent acute shortages of fertilizer during the main cropping season and started encouraging the domestic production of fertilizer and investments in the fertilizer industries of neighboring countries.

The most recent major policy shift occurred in 2009, and it has guided Nepali fertilizer policies up to today. The government reintroduced the subsidy for chemical fertilizer. This was likely in response to both a seeming increase in the real price of chemical fertilizer observed since 2008 and the growing perception of quality adulteration of fertilizer traded in the private markets supplied outside government schemes. By directly procuring and distributing chemical fertilizer at a subsidized price, the government aims to both contain the price of chemical fertilizer and maintain its quality. Currently, most of the formal-sector channel supplying fertilizer is government owned - that is, through the Agriculture Inputs Company Limited and the National Salt Trading Corporation - and under government subsidy, although the majority of chemical fertilizer used in Nepal is still obtained through informal channels (Pandey 2013; ADB 2013). The government still provides a transportation subsidy for chemical fertilizer for 26 remote districts, as per the chemical fertilizer and seed transportation subsidy directives, 2069. 


\section{KEY PATTERNS OF FERTILIZER USE IN NEPAL}

\section{Inorganic and Organic Fertilizer Use}

In mountainous regions like Nepal (particularly in the Hills and the Mountains belts), the potential and technologies for increased use of manure have major implications on the demand for inorganic fertilizer, unlike in other countries with a relatively more flat terrain, although the reason for this does not seem to have been empirically investigated. Table 3.1 provides some international perspective with a primary focus on countries with high terrain ruggedness as defined in Nunn and Puga (2012). Columns 4 and 5 report the nitrogen use (in kilograms) per hectare of arable land in 2009-2012 from manure and chemical fertilizer, respectively (except Nepal, where we report the annually cultivated area calculated from the NLSS), and column 6 reports the ratio of nitrogen sourced from manure to that from synthetic fertilizer. Given the growth in the world's consumption of synthetic fertilizer, the nitrogen used in agriculture sourced from synthetic fertilizer is generally much higher than the nitrogen sourced from manure (more than four times higher in the world: 83 kilograms/hectare compared to 19 kilograms/hectare). This is also the common trend in most countries with relatively flat terrain. ${ }^{2}$ However, in rugged regions of the world, manure nitrogen often accounts for a much greater share of total nitrogen use. Switzerland is a noticeable example, where the use of manure nitrogen is 1.44 times greater than that of synthetic fertilizer nitrogen. In the Nepal Hills, manure nitrogen use (22 kilograms/hectare) outpaces nitrogen from synthetic fertilizer (13 kilograms/hectare). In parts of the midHills, manure often provided 100 kilograms of nitrogen per hectare per year in the 1990s (Thorne and Tanner 2002). Analysis of the adoption of inorganic fertilizer in Nepal must take into account such potential and farmers' demand for both inorganic fertilizer and manure.

In FAOSTAT, manure nitrogen production by cattle in Nepal is assumed to be less efficientonly 4 kilograms of manure nitrogen per cow, compared with 50 in Europe (Switzerland, for example) and 22 in China. While it is beyond the scope of this paper, technological improvements, such as those used in Europe, can potentially increase the industrial supply of manure/compost in Nepal, which may have important implications for fertilizer policies, particularly in the Hills region.

It is, however, important to note that, even taking manure into account, overall nitrogen use in Nepal seems lower than in other countries; use of inorganic fertilizer per cultivated area is still much lower than in Bangladesh or India. Overall nitrogen use is lower than in other hilly regions in the world (this is particularly so given that in Nepal, most land is cultivated twice per year so that actual land use is often much greater than the arable land reported in FAOSTAT).

${ }^{2}$ In India (for example, in Tamil Nadu), farmyard manure-based technology may be limited to a small area around the animals (Kajisa and Palanichamy 2011). 
Table 3.1 Nitrogen use in mountainous/hilly parts of the world ${ }^{a}$

\begin{tabular}{|c|c|c|c|c|c|c|c|}
\hline & Ruggedness & $\begin{array}{c}\text { Rugged-ness } \\
\text { (population } \\
\text { weighted) } \\
\end{array}$ & $\begin{array}{c}\text { GDP per } \\
\text { capita, current } \\
\text { USD, } 2013 \\
\end{array}$ & $\begin{array}{c}\text { Manure N kg/ha } \\
\text { of arable land } \\
(2009-2012)^{\#} \\
\end{array}$ & $\begin{array}{c}\text { Synthetic fertilizer N } \\
\mathrm{kg} / \mathrm{ha} \text { of arable land } \\
(2009-2012)^{\#}\end{array}$ & $\begin{array}{c}\text { Ratio = manure } \\
\text { N/synthetic } \\
\text { fertilizer } N\end{array}$ & $\begin{array}{c}\text { Manure N per } \\
\text { cow (2012) }\end{array}$ \\
\hline \multicolumn{8}{|c|}{ Countries with higher share of nitrogen from manure } \\
\hline Nepal & 5.04 & 1.26 & 694 & $17^{\mathrm{b}}$ & $26^{\mathrm{bc}}$ & 0.65 & 4 \\
\hline Nepal Terai & & & & $11^{\mathrm{b}}$ & $38^{\mathrm{bc}}$ & 0.29 & \\
\hline Nepal Hills & & & & $22^{\mathrm{b}}$ & $13^{\mathrm{bc}}$ & 1.69 & \\
\hline Albania & 3.43 & 1.60 & 4,659 & 53 & 55 & 0.96 & 53 \\
\hline Austria & 3.51 & 1.15 & 50,547 & 70 & 62 & 1.13 & 48 \\
\hline Azerbaijan & 1.67 & 0.53 & 7,812 & 19 & 5 & 3.76 & 33 \\
\hline Bolivia & 0.85 & 0.91 & 2,868 & 18 & 5 & 3.76 & 1 \\
\hline Georgia & 3.66 & 0.86 & 3,605 & 63 & 27 & 2.33 & 32 \\
\hline Greece & 3.10 & 1.30 & 21,956 & 26 & 58 & 0.45 & 50 \\
\hline Italy & 2.46 & 0.76 & 35,926 & 58 & 81 & 0.72 & 49 \\
\hline Korea (South) & 1.96 & 0.75 & 25,977 & 76 & 155 & 0.49 & 20 \\
\hline Macedonia & 2.67 & 0.89 & 4,839 & 34 & 43 & 0.79 & 48 \\
\hline New Zealand & 2.04 & 0.45 & 41,556 & & & 5.67 & 13 \\
\hline Norway & 2.41 & 1.25 & 100,819 & 51 & 113 & 0.45 & 48 \\
\hline Switzerland & 4.76 & 1.45 & 84,815 & 177 & 123 & 1.44 & 53 \\
\hline \multicolumn{8}{|c|}{ Countries with lower share of nitrogen from manure } \\
\hline Argentina & 0.78 & 0.22 & 14,715 & 4 & 22 & 0.18 & 2 \\
\hline Australia & 0.14 & 0.18 & 67,458 & 3 & 20 & 0.15 & 6 \\
\hline Bangladesh & 0.19 & 0.07 & 958 & 29 & 153 & 0.19 & 5 \\
\hline Brazil & 0.24 & 0.25 & 11,208 & 21 & 54 & 0.39 & 5 \\
\hline China & 1.88 & 0.71 & 6,807 & 52 & 371 & 0.14 & 22 \\
\hline India & 1.01 & 0.24 & 1,499 & 15 & 107 & 0.14 & 5 \\
\hline Japan & 2.13 & 0.46 & 38,634 & 37 & & 0.37 & 25 \\
\hline Mexico & 1.73 & 0.83 & 10,307 & 15 & 54 & 0.28 & 4 \\
\hline Turkey & 2.62 & 1.19 & 10,972 & 15 & 68 & 0.22 & 30 \\
\hline Vietnam & 2.05 & 0.44 & 1,911 & 44 & 176 & 0.25 & 20 \\
\hline USA & 1.07 & 0.33 & 53,042 & 15 & 75 & 0.20 & 16 \\
\hline World & & & & 19 & 83 & 0.23 & 12 \\
\hline
\end{tabular}




\section{Trends over Time and Regional Variations of Fertilizer Use Assessed from the NLSS}

\section{Use of Inorganic Fertilizer}

Use of inorganic fertilizer has increased in Nepal, particularly between 2003 and 2010, from 262,000 metric tons to 409,000 metric tons with statistical significance (Table 3.2). Much of this increase came from the Terai (171,000 metric tons to 322,000 metric tons) while no statistically significant increase has been observed in the Hills and Mountains.

Table 3.2 Total inorganic fertilizer use (1,000 metric tons)

\begin{tabular}{lrrr}
\hline & $\mathbf{1 9 9 5}$ & $\mathbf{2 0 0 3}$ & $\mathbf{2 0 1 0}$ \\
\hline Total Nepal & $\mathbf{2 0 9 \pm \mathbf { 3 8 }}$ & $\mathbf{2 6 2} \pm \mathbf{4 6}$ & $\mathbf{4 0 9 \pm \mathbf { 7 0 }}$ \\
\hline Terai & $146 \pm 30$ & $171 \pm 37$ & $322 \pm 61$ \\
Eastern & $28 \pm 9$ & $45 \pm 19$ & $82 \pm 25$ \\
Central & $52 \pm 19$ & $60 \pm 16$ & $152 \pm 49$ \\
Western & $35 \pm 10$ & $34 \pm 23$ & $50 \pm 15$ \\
Mid-Western & $22 \pm 19$ & $15 \pm 10$ & $19 \pm 7$ \\
Far-Western & $8 \pm 8$ & $17 \pm 17$ & $19 \pm 15$ \\
\hline Hills & $55 \pm 15$ & $76 \pm 24$ & $78 \pm 20$ \\
\hline Mountains & $9 \pm 5$ & $15 \pm 7$ & $9 \pm 5$ \\
\hline
\end{tabular}

Source: Authors' calculations based on the NLSS 1995, 2003, and 2010.

Note: Margins of error are adjusted for cluster sample with enumeration area as the cluster.

The growth in inorganic fertilizer use in Nepal is partly reflected by the growth in the share of farm households using it, from 53 percent in 1995 to 61 percent in 2003 to 69 percent in 2010 (Table 3.3). Again, the increase in that share has been led by the growth in the Terai (66 percent in 2003 to 79 percent in 2010).

Table 3.3 also reports annual consumption of inorganic fertilizer per hectare of cultivated area and per farm household. Relative to the share of farm households using fertilizer, quantities used exhibit greater variations across ecological belts as well as across regions. In the Terai, consumption increased from 48 kilograms and 63 kilograms per hectare in 1995 and 2003 to 117 kilograms per hectare in 2010, while it remained fairly stagnant in the Hills and even declined in the Mountains. In both the Terai and the Hills, the central region exhibits considerably higher use of inorganic fertilizer (159 kilograms per hectare in the central Terai, and 99 kilograms per hectare in the central Hills, both in 2010) than other regions within the ecological belts.

Additionally, in the Terai, the average quantity per farm household is relatively larger than the average quantity per hectare, compared with the Hills and the Mountains (for example, $169 / 117$ in the Terai versus $36 / 37$ in the Hills). This is primarily because land use intensity is higher in the Terai (average cultivated area in two seasons compared with land owned), indicating that in the Terai, farmers use more of both inorganic nutrients and land. ${ }^{3}$

\footnotetext{
${ }^{3}$ Note that the estimates of manure used here are based on the household endowment of each type of livestock, rather than the actual measures of quantities used. The actual usage of manure must be estimated by separate surveys. The lower livestock holdings in the Terai versus those in the Hills or Mountains implies lower manure usage in the Terai. While future studies must investigate the reasons for lower livestock holdings in the Terai zone, possible reasons may include the hotter and more humid climate in the Terai, which sometimes leads to greater incidence of livestock diseases.
} 
Table 3.3 Use of inorganic fertilizer at farm household level

\begin{tabular}{|c|c|c|c|c|c|c|c|c|c|}
\hline \multirow[b]{2}{*}{ Region } & \multicolumn{3}{|c|}{$\begin{array}{c}\% \text { of farm households using } \\
\text { inorganic fertilizer }\end{array}$} & \multicolumn{3}{|c|}{$\begin{array}{l}\text { Kilograms per hectare of } \\
\text { cultivated area, annual }^{\text {b }}\end{array}$} & \multicolumn{3}{|c|}{$\begin{array}{l}\text { Kilograms per farm } \\
\text { household, annual }\end{array}$} \\
\hline & 1995 & 2003 & 2010 & 1995 & 2003 & 2010 & 1995 & 2003 & 2010 \\
\hline Nepal & $53 \pm 4$ & $61 \pm 4$ & $69 \pm 3$ & $36 \pm 3$ & $53 \pm 4$ & $76 \pm 6$ & $69 \pm 6$ & $80 \pm 6$ & $93 \pm 9$ \\
\hline Terai & $57 \pm 5$ & $66 \pm 4$ & $79 \pm 3$ & $48 \pm 4$ & $63 \pm 6$ & $117 \pm 10$ & $114 \pm 13$ & $118 \pm 12$ & $169 \pm 19$ \\
\hline Eastern & $42 \pm 7$ & $57 \pm 8$ & $74 \pm 6$ & $34 \pm 6$ & $47 \pm 10$ & $95 \pm 14$ & $91 \pm 22$ & $106 \pm 21$ & $141 \pm 27$ \\
\hline Central & $60 \pm 9$ & $69 \pm 6$ & $80 \pm 5$ & $56 \pm 7$ & $88 \pm 9$ & $159 \pm 23$ & $104 \pm 21$ & $123 \pm 16$ & $237 \pm 47$ \\
\hline Western & $77 \pm 9$ & $81 \pm 8$ & $88 \pm 5$ & $61 \pm 8$ & $79 \pm 13$ & $123 \pm 13$ & $152 \pm 35$ & $139 \pm 42$ & $177 \pm 25$ \\
\hline Mid-Western & $59 \pm 23$ & $64 \pm 17$ & $78 \pm 9$ & $61 \pm 20$ & $49 \pm 14$ & $70 \pm 14$ & $167 \pm 49$ & $98 \pm 28$ & $86 \pm 18$ \\
\hline Far-Western & $46 \pm 28$ & $66 \pm 21$ & $78 \pm 6$ & $25 \pm 9$ & $52 \pm 17$ & $77 \pm 25$ & $77 \pm 36$ & $120 \pm 50$ & $103 \pm 38$ \\
\hline Hills & $52 \pm 7$ & $59 \pm 6$ & $61 \pm 5$ & $26 \pm 4$ & $42 \pm 6$ & $36 \pm 4$ & $37 \pm 4$ & $50 \pm 7$ & $37 \pm 4$ \\
\hline Eastern & $36 \pm 7$ & $43 \pm 6$ & $58 \pm 5$ & $7 \pm 2$ & $18 \pm 6$ & $21 \pm 4$ & $15 \pm 5$ & $28 \pm 25$ & $33 \pm 7$ \\
\hline Central & $80 \pm 4$ & $88 \pm 3$ & $86 \pm 3$ & $73 \pm 11$ & $113 \pm 12$ & $99 \pm 16$ & $86 \pm 11$ & $120 \pm 16$ & $89 \pm 13$ \\
\hline Western & $61 \pm 5$ & $60 \pm 5$ & $65 \pm 4$ & $24 \pm 6$ & $21 \pm 5$ & $20 \pm 4$ & $23 \pm 6$ & $22 \pm 5$ & $16 \pm 2$ \\
\hline Mid-Western & $40 \pm 8$ & $49 \pm 7$ & $44 \pm 5$ & $13 \pm 7$ & $13 \pm 5$ & $13 \pm 3$ & $21 \pm 8$ & $16 \pm 4$ & $13 \pm 3$ \\
\hline Far-Western & $23 \pm 7$ & $43 \pm 12$ & $35 \pm 7$ & $5 \pm 3$ & $6 \pm 2$ & $7 \pm 3$ & $10 \pm 6$ & $6 \pm 3$ & $8 \pm 3$ \\
\hline Mountains & $40 \pm 14$ & $47 \pm 15$ & $52 \pm 16$ & $15 \pm 5$ & $31 \pm 6$ & $20 \pm 5$ & $31 \pm 6$ & $49 \pm 9$ & $25 \pm 5$ \\
\hline
\end{tabular}

Source: Authors' calculations based on the NLSS.

Note: Farm households here include small fractions of landless households that only provide agricultural workers. Margins of error are adjusted for cluster sample with enumeration area as the cluster. ${ }^{\text {a }}$ Figures for the percentage shares are weighted by sample weights. ${ }^{b}$ Weighted by the sample weights as well as cultivated area (annual).

A majority of inorganic fertilizer used is urea and DAP, while little complex fertilizer is used (Table 3.4). In the Terai, consumption of urea per hectare of cultivated area increased from 28 kilograms in 1995 to 38 kilograms in 2003 to 63 kilograms in 2010, while consumption of DAP increased from 17 kilograms in 1995 to 23 kilograms in 2003 to 47 kilograms in 2010.

Table 3.4 Inorganic fertilizer use (kilograms/hectare of cultivated area, annual)

\begin{tabular}{|c|c|c|c|c|}
\hline Country/Belt & Type & 1995 & 2003 & 2010 \\
\hline \multirow[t]{4}{*}{ Nepal } & Urea & $23 \pm 4$ & $35 \pm 5$ & $43 \pm 5$ \\
\hline & Complex & $3 \pm 1$ & $1 \pm 1$ & $1 \pm 1$ \\
\hline & DAP & $10 \pm 3$ & $16 \pm 3$ & $29 \pm 5$ \\
\hline & Others & $0 \pm 0$ & $0 \pm 0$ & $3 \pm 1$ \\
\hline \multirow[t]{4}{*}{ Terai } & Urea & $28 \pm 5$ & $38 \pm 6$ & $63 \pm 7$ \\
\hline & Complex & $3 \pm 2$ & $2 \pm 1$ & $2 \pm 1$ \\
\hline & DAP & $17 \pm 4$ & $23 \pm 4$ & $47 \pm 7$ \\
\hline & Others & $0 \pm 0$ & $0 \pm 0$ & $5 \pm 2$ \\
\hline \multirow[t]{4}{*}{ Hills } & Urea & $18 \pm 6$ & $33 \pm 9$ & $24 \pm 5$ \\
\hline & Complex & $4 \pm 2$ & $1 \pm 1$ & $0 \pm 0$ \\
\hline & DAP & $3 \pm 2$ & $9 \pm 4$ & $10 \pm 4$ \\
\hline & Others & $0 \pm 0$ & $0 \pm 0$ & $1 \pm 1$ \\
\hline \multirow[t]{4}{*}{ Mountains } & Urea & $12 \pm 8$ & $27 \pm 14$ & $15 \pm 6$ \\
\hline & Complex & $2 \pm 2$ & $0 \pm 0$ & $0 \pm 0$ \\
\hline & DAP & $1 \pm 1$ & $5 \pm 3$ & $4 \pm 6$ \\
\hline & Others & $0 \pm 0$ & $0 \pm 0$ & $1 \pm 0$ \\
\hline
\end{tabular}

Source: Authors' calculations based on the NLSS 1995, 2003, and 2010.

Note: Weighted by the sample weights as well as cultivated area (annual). Margins of error are adjusted for cluster sample with enumeration area as the cluster. 


\section{Nutrients_-Inorganic and Organic}

As was briefly described earlier, unlike in many countries, farmers in Nepal may rely relatively more on livestock manure for farm nutrients, particularly in the Hills and the Mountains. Table 3.5 provides some estimates of the use of three major nutrients sourced from inorganic fertilizer as well as manure. These are only rough estimates based on the typical chemical composition of inorganic fertilizer distributed in the South Asia region, as well as the typical quantities of nutrients derived from manure, which are assessed from national-level figures and interpolated into the NLSS data. NLSS data provide neither of such information, and all figures must be verified in future studies (see the appendix for the methodologies used to calculate the nutrient composition of inorganic and organic fertilizer).

Table 3.5 Estimated nitrogen, phosphate, and potassium use (kilograms per farm household per year)

\begin{tabular}{|c|c|c|c|c|c|c|c|c|}
\hline \multirow[t]{2}{*}{ Variable } & \multirow[t]{2}{*}{ Nutrient } & \multirow[t]{2}{*}{ Belt } & \multicolumn{2}{|c|}{1995} & \multicolumn{2}{|c|}{2003} & \multicolumn{2}{|c|}{2010} \\
\hline & & & Inorganic & Manure & Inorganic & Manure & Inorganic & Manure \\
\hline \multirow{12}{*}{$\begin{array}{l}\text { Kilograms } \\
\text { per farm } \\
\text { household } \\
\text { per year }\end{array}$} & Nitrogen & Nepal & 24 & 25 & 29 & 23 & 31 & 20 \\
\hline & & Terai & 38 & 23 & 40 & 18 & 55 & 16 \\
\hline & & Hills & 14 & 26 & 20 & 26 & 13 & 23 \\
\hline & & Mountains & 12 & 28 & 20 & 29 & 10 & 24 \\
\hline & Phospha & Nepal & 10 & 6 & 12 & 5 & 17 & 5 \\
\hline & & Terai & 20 & 5 & 21 & 4 & 34 & 4 \\
\hline & & Hills & 4 & 6 & 5 & 6 & 5 & 5 \\
\hline & & Mountains & 2 & 6 & 4 & 6 & 3 & 6 \\
\hline & $\begin{array}{l}\text { Potassiu } \\
\mathrm{m}\end{array}$ & Nepal & 1 & 27 & 0 & 25 & 0 & 22 \\
\hline & & Terai & 1 & 25 & 0 & 20 & 1 & 18 \\
\hline & & Hills & 1 & 29 & 0 & 28 & 0 & 26 \\
\hline & & Mountains & 1 & 32 & 0 & 33 & 0 & 27 \\
\hline \multirow{12}{*}{$\begin{array}{l}\text { Kilograms } \\
\text { per } \\
\text { cultivated } \\
\text { area } \\
\text { (hectares) } \\
\text { per year }\end{array}$} & Nitrogen & Nepal & 13 & 13 & 19 & 15 & 25 & 16 \\
\hline & & Terai & 16 & 10 & 22 & 10 & 38 & 11 \\
\hline & & Hills & 10 & 18 & 16 & 22 & 13 & 22 \\
\hline & & Mountains & 6 & 13 & 13 & 18 & 8 & 19 \\
\hline & Phospha & Nepal & 5 & 3 & 8 & 3 & 14 & 4 \\
\hline & & Terai & 9 & 2 & 11 & 2 & 23 & 3 \\
\hline & & Hills & 2 & 4 & 4 & 5 & 5 & 5 \\
\hline & & Mountains & 1 & 3 & 2 & 4 & 2 & 4 \\
\hline & $\begin{array}{l}\text { Phospha } \\
\text { te }\end{array}$ & Nepal & 1 & 14 & 0 & 17 & 0 & 18 \\
\hline & & Terai & 1 & 11 & 0 & 11 & 1 & 12 \\
\hline & & Hills & 1 & 20 & 0 & 24 & 0 & 25 \\
\hline & & Mountains & 0 & 15 & 0 & 21 & 0 & 22 \\
\hline
\end{tabular}

Source: Authors' calculations using the NLSS.

Note: Farm households here are defined as households reporting positive areas cultivated. They exclude households that provide only agricultural laborers that are hired by other farm households.

Based on the estimate, we see certain patterns in nutrient use. First, some of the chemical nutrient deficiencies in the Hills and Mountains are offset (though not entirely) by the use of manure; in 2010, nitrogen from manure was applied at a rate of 22 kilograms per hectare of cultivated area in the Hills and 19 kilograms in the Mountains as opposed to 11 kilograms in the Terai, while nitrogen from inorganic fertilizer was applied at 13 kilograms and 8 kilograms, respectively, as opposed to 38 kilograms in the Terai. The greater role of manure than chemical fertilizer as the source of nitrogen is 
consistent with earlier studies. ${ }^{4}$ Second, most potassium might be obtained from manure rather than inorganic fertilizer. For Nepal as a whole, an average farm household applied less than 1 kilogram of potassium from inorganic fertilizer per year, but given livestock holdings and typical nutrients extracted, the household can be applying 22 kilograms of potassium from manure.

As we discussed earlier, overall nutrient use per cultivated area is still low in Nepal, even when we take manure nutrients into account. However, the relative importance of manure nutrients should be considered when assessing the demand for inorganic fertilizer, particularly in the Hills and Mountains, relative to the Terai where cattle manure is mostly used as cooking fuel.

An important distinction between chemical fertilizer use intensity between the Terai and the Hills excluding the central region is its relation with the size of the cultivated area. Figure 3.1 shows the local polynomial regression of chemical nutrient use per hectare on the cultivated area and confidence intervals of the estimates in the Terai and the Hills excluding the central region. While the intensity of chemical fertilizer use drops rapidly as the size of cultivated area per household rises in the latter region, the rate of that reduction is much slower in the Terai region. In other words, part of the difference in chemical fertilizer use intensity between the Terai and the Hills accrues to the differences in the intensity of use among the medium-to-large-size farms.

Figure 3.1 Significant relationship between differences in chemical fertilizer intensity and farm size in the Terai and in the Hills excluding the central region

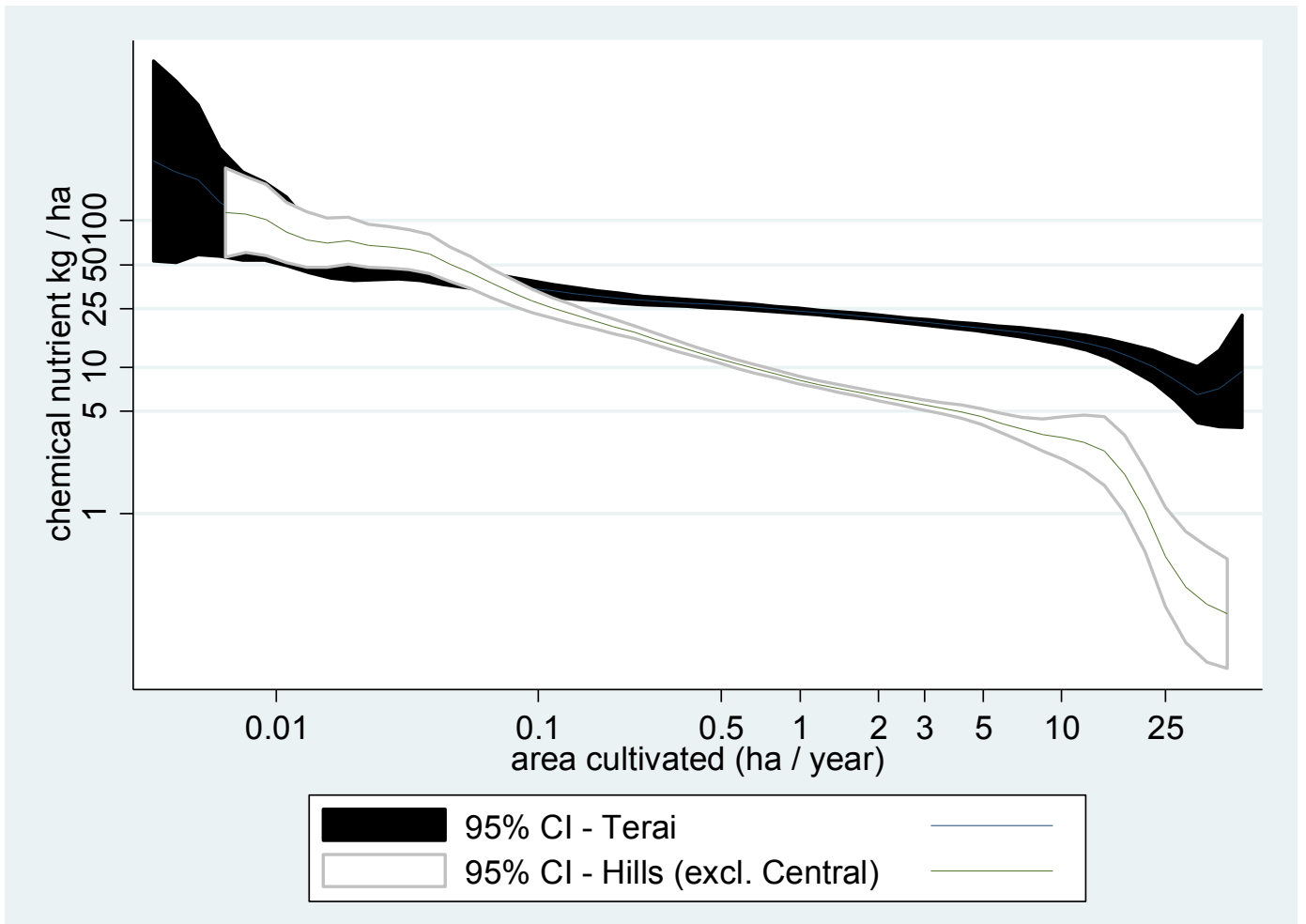

Source: Authors' estimation based on NLSS data. CI = confidence interval.

${ }^{4}$ For example, Pilbeam et al. (2000) reported that manure provided four times more nitrogen than chemical fertilizer in the mid-Hills in the late 1990s. 
Table 3.6 presents the price of urea in each agroecological belt (and region within the Terai), averaged across all farm households reporting the price (weighted by the sample weights). Real prices of urea and DAP are first calculated for farmers reporting the purchase quantities and prices, and then replaced with the VDC-level median if the VDC median value is available from the sample, the districtlevel median if the district median value is available from the sample but the VDC median value is not, and the regional median and zonal median and so on. Real prices are approximated by dividing the fertilizer price by the average prices of rice and wheat, two major staples in Nepal.

Table 3.6 Urea price by region

\begin{tabular}{lcccccc}
\hline & \multicolumn{3}{c}{ Nominal, rupees per kg } & \multicolumn{3}{c}{ Urea price per kg / cereal price per kg } \\
\cline { 2 - 7 } Region & $\mathbf{1 9 9 5}$ & $\mathbf{2 0 0 3}$ & $\mathbf{2 0 1 0}$ & $\mathbf{1 9 9 5}$ & $\mathbf{2 0 0 3}$ & $\mathbf{2 0 1 0}$ \\
\hline Terai & $6.8 \pm 0.3$ & $12.9 \pm 0.4$ & $19.4 \pm 0.9$ & $1.10 \pm 0.05$ & $1.51 \pm 0.05$ & $1.18 \pm 0.06$ \\
\cline { 2 - 7 } Eastern & $7.7 \pm 1.0$ & $12.5 \pm 0.8$ & $16.9 \pm 1.2$ & $1.25 \pm 0.16$ & $1.44 \pm 0.10$ & $1.02 \pm 0.07$ \\
Central & $6.7 \pm 0.3$ & $12.6 \pm 0.8$ & $16.9 \pm 1.3$ & $1.06 \pm 0.05$ & $1.47 \pm 0.10$ & $1.03 \pm 0.08$ \\
Western & $6.3 \pm 0.4$ & $13.5 \pm 0.6$ & $21.5 \pm 1.5$ & $1.03 \pm 0.07$ & $1.62 \pm 0.07$ & $1.31 \pm 0.09$ \\
Mid-Western & $6.2 \pm 0.3$ & $13.9 \pm 0.7$ & $27.9 \pm 2.7$ & $1.06 \pm 0.06$ & $1.64 \pm 0.09$ & $1.72 \pm 0.17$ \\
Far-Western & $7.1 \pm 1.2$ & $12.9 \pm 0.6$ & $23.9 \pm 1.5$ & $1.17 \pm 0.20$ & $1.62 \pm 0.11$ & $1.49 \pm 0.09$ \\
\hline Hills & $7.0 \pm 0.4$ & $16.7 \pm 0.4$ & $27.7 \pm 0.9$ & $1.01 \pm 0.05$ & $1.69 \pm 0.04$ & $1.55 \pm 0.05$ \\
\hline Mountains & $7.0 \pm 1.1$ & $17.0 \pm 1.1$ & $30.3 \pm 2.5$ & $0.98 \pm 0.14$ & $1.87 \pm 0.10$ & $1.77 \pm 0.15$ \\
\hline Nepal & $6.9 \pm 0.2$ & $14.7 \pm 0.4$ & $23.4 \pm 0.8$ & $1.05 \pm 0.04$ & $1.61 \pm 0.04$ & $1.36 \pm 0.05$ \\
\hline
\end{tabular}

Source: Authors' calculations based on the NLSS 1995, 2003, and 2010.

Note: Weighted by the sample weights. Margins of error are adjusted for cluster sample with enumeration area as the cluster. $\mathrm{kg}=$ kilogram.

The real price of inorganic fertilizer (measured in kilograms of cereals) generally rose considerably between 1995 and 2003 (price of a kilogram of urea equivalent to 1.05 kilograms of cereals in 1995 to 1.61 in 2003) and declined between 2003 and 2010 (1.61 to 1.36). The decline in the real price between 2003 and 2010 is despite a significant increase in the nominal price during that period. This is because the nominal price of cereals increased even more during that period. The extent of the decrease in real price was particularly large in the Terai, with the eastern and central regions experiencing almost a 30 percent decline between 2003 and 2010. The extent of the price decrease in the other regions within the Terai, as well as in the Hills and the Mountains, has been slower. The patterns are similar for DAP (Table 3.7).

Table 3.7 DAP price by region

\begin{tabular}{lcccccc}
\hline & \multicolumn{3}{c}{ Nominal, rupee per kg } & \multicolumn{3}{c}{ DAP price per kg / cereal price per kg } \\
\hline Region & 1995 & 2003 & 2010 & 1995 & 2003 & 2010 \\
\hline Terai & 12.6 & 20.1 & 32.1 & 2.05 & 2.34 & 1.97 \\
Eastern & 12.0 & 19.7 & 28.8 & 1.94 & 2.26 & 1.76 \\
Central & 12.8 & 20.1 & 30.2 & 2.05 & 2.34 & 1.84 \\
Western & 12.7 & 20.1 & 35.1 & 2.06 & 2.38 & 2.15 \\
Mid-Western & 13.0 & 19.7 & 40.1 & 2.18 & 2.30 & 2.47 \\
Far-Western & 13.9 & 21.8 & 38.0 & 2.27 & 2.66 & 2.36 \\
\hline Hills & 13.0 & 22.9 & 39.0 & 1.87 & 2.33 & 2.11 \\
\hline Mountains & 13.2 & 22.7 & 42.3 & 1.81 & 2.48 & 2.47 \\
\hline Nepal & 12.9 & 21.5 & 36.1 & 1.95 & 2.35 & 2.07 \\
\hline
\end{tabular}

Source: Authors' calculations based on the NLSS 1995, 2003, and 2010.

Note: Weighted by the sample weights. 


\section{Fertilizer Use and Crops}

Although the NLSS does not report quantities of fertilizer used for each crop, it reports for which crops fertilizer was mainly used. Figure 3.2 presents the share (percentage) of farm households growing major crops and using fertilizer for each crop. Crops listed in Figure 3.2 account for most of the fertilizer use.

Figure 3.2 Major crops for which inorganic fertilizer is used, by agroecological belt, year

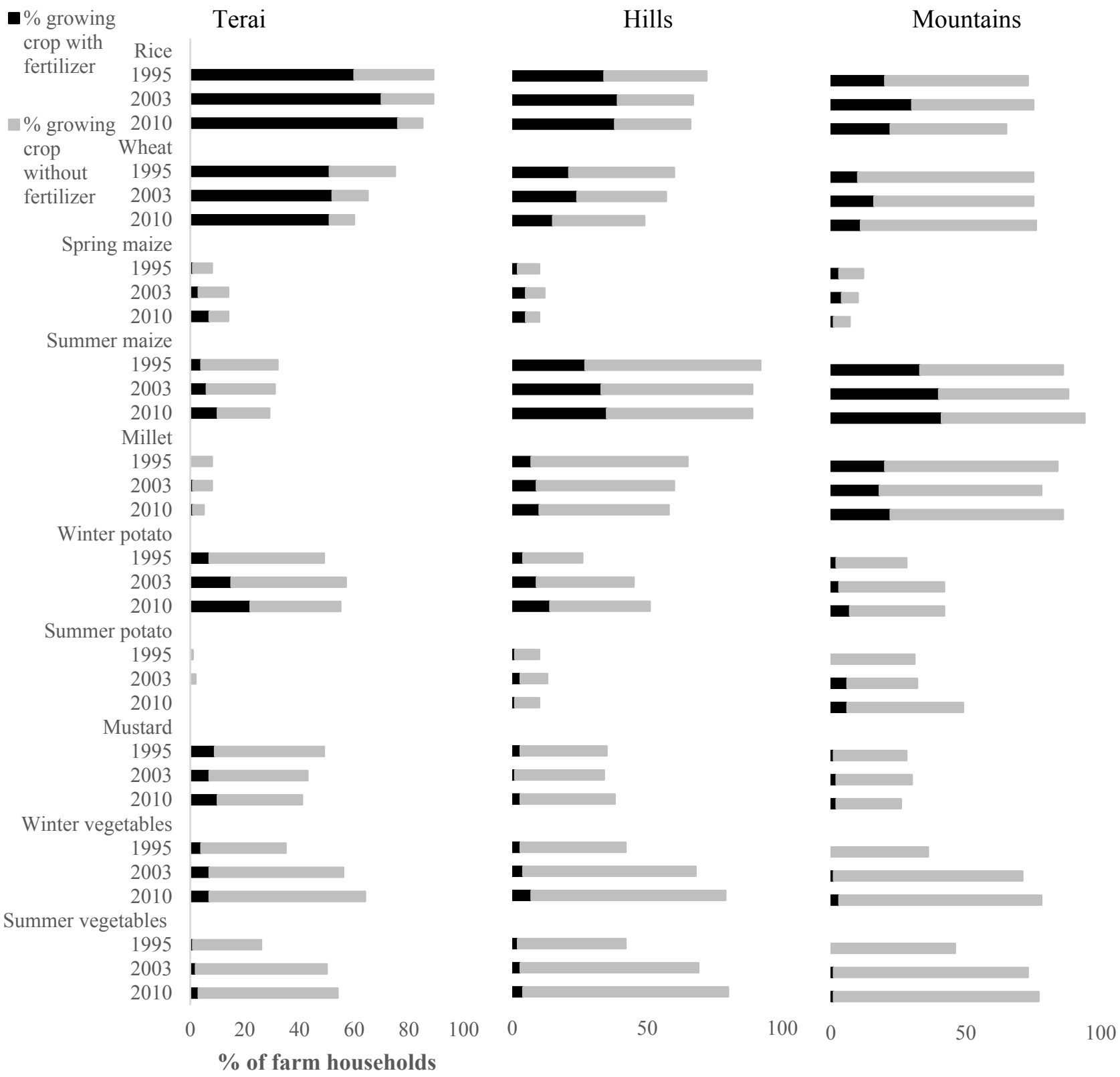

Source: Authors' estimations based on the NLSS.

Some variations are observed across crops as well as agroecological belts. In the Terai, most rice and wheat growers apply inorganic fertilizer to those crops, while few growers of other crops apply inorganic fertilizer to those crops. Use of inorganic fertilizer seems, however, to be on the rise for certain crops such as winter potato, vegetables, and sugarcane. 
In the Hills, most households apply inorganic fertilizer to rice, vegetables on a commercial scale, and summer maize. Farmers applying inorganic fertilizer are, however, a relative minority among summer maize growers. Use of inorganic fertilizer on wheat seems to be declining in the Hills. In the Mountains, patterns are similar to those of the Hills. In the Mountains, millet is as commonly grown as rice and receives more fertilizer compared with crops like wheat. ${ }^{5}$

\section{Seemingly Increased Use of Manure (Local Fertilizer) in the Hills and Mountains Based on the Census}

An organic fertilizer like manure is not only important but appears to be increasingly used in the Hills and the Mountains. Table 3.8 shows the ratio of growers of each crop using manure only to growers using chemical fertilizer, assessed from the Nepal Agricultural Census 2001 and 2011 (Nepal CBS 2001, $2011 b$ ). While the two rounds of the census may employ different definitions of manure and fertilizer as well as different interview methods, and variations must be interpreted carefully, the variations across crops and regions are insightful. For example, for Nepal as a whole, in 2011 for every rice grower using chemical fertilizer on rice, there was 0.5 rice grower using manure only on rice, a decrease from 0.6 in 2001, indicating that between 2001 and 2011, rice growers using manure only have become relatively more minor than those using chemical fertilizer. The patterns are different for other crops, such as maize and potato. According to the 2011 census, growers of those crops used manure only 1.6 times more than growers used chemical fertilizer. For vegetables, the ratio was 2.1 in 2001 but 4.2 in 2011, indicating growing reliance on manure for vegetable production. These patterns are more pronounced in the Hills and the Mountains. Although these figures do not account for the average quantities of manure and chemical fertilizer used and are only indicative, they are consistent with our earlier remark that manure plays an important role in the demand for chemical fertilizer in Nepal.

Table 3.8 Ratio of households using manure only to households using chemical fertilizer, by crop

\begin{tabular}{|c|c|c|c|c|c|c|c|}
\hline Zone & $\begin{array}{c}\text { Census } \\
\text { year }\end{array}$ & Paddy & Maize & Wheat & Potato & Vegetables & Other \\
\hline \multirow[t]{2}{*}{ Terai } & 2001 & 0.2 & 1.9 & 0.2 & 0.6 & 1.5 & 1.4 \\
\hline & 2011 & 0.1 & 1.2 & 0.2 & 0.9 & 2.5 & 3.5 \\
\hline \multirow[t]{2}{*}{ Hills } & 2001 & 1.0 & 1.7 & 1.5 & 2.1 & 2.4 & 3.3 \\
\hline & 2011 & 1.1 & 1.8 & 2.6 & 2.7 & 5.4 & 10.0 \\
\hline \multirow{2}{*}{ Eastern } & 2001 & 2.1 & 2.4 & 1.2 & 3.0 & 4.4 & 10.6 \\
\hline & 2011 & 2.2 & 2.6 & 3.0 & 6.8 & 25.0 & 50.0 \\
\hline \multirow[t]{2}{*}{ Central } & 2001 & 0.1 & 0.2 & 0.2 & 0.4 & 0.6 & 0.7 \\
\hline & 2011 & 0.2 & 0.3 & 0.4 & 0.7 & 1.7 & 3.1 \\
\hline \multirow[t]{2}{*}{ Western } & 2001 & 1.0 & 2.4 & 1.3 & 2.0 & 3.1 & 7.5 \\
\hline & 2011 & 1.1 & 2.2 & 2.1 & 2.8 & 9.1 & 20.0 \\
\hline \multirow{2}{*}{$\begin{array}{l}\text { Mid- } \\
\text { Western }\end{array}$} & 2001 & 2.5 & 14.0 & 5.5 & 7.1 & 7.7 & 23.5 \\
\hline & 2011 & 2.3 & 10.0 & 5.3 & 6.7 & 12.5 & 100.0 \\
\hline \multirow{2}{*}{$\begin{array}{l}\text { Far- } \\
\text { Western }\end{array}$} & 2001 & 5.6 & 8.7 & 4.8 & 9.8 & 5.5 & 7.9 \\
\hline & 2011 & 6.3 & 16.7 & 7.1 & 33.3 & 50.0 & 100.0 \\
\hline \multirow[t]{2}{*}{ Mountains } & 2001 & 2.8 & 2.6 & 5.0 & 6.0 & 10.7 & 5.8 \\
\hline & 2011 & 2.2 & 1.5 & 4.5 & 4.9 & 10.0 & 5.6 \\
\hline \multirow[t]{2}{*}{ All } & 2001 & 0.6 & 1.8 & 0.8 & 1.4 & 2.1 & 2.4 \\
\hline & 2011 & 0.5 & 1.6 & 0.8 & 1.6 & 4.2 & 5.9 \\
\hline
\end{tabular}

Source: Agricultural Census 2001-2002 and 2011-2012.

Note: The census also captures households using both chemical fertilizer and manure. Those households are included under "chemical fertilizer."

\footnotetext{
${ }^{5}$ It is beyond the scope of this paper to investigate the causes of these patterns. Future studies must investigate why these patterns vary across ecological belts and across crops.
} 


\section{Sources of Chemical Fertilizer}

The adulteration of fertilizer is sometimes considered an issue in low-income countries with weak capacity for fertilizer quality regulation. The quality of chemical fertilizer, which is often unobservable, can vary systematically across households. The NLSS does not report the fertilizer quality or farmers' assessment of such quality. However, considering the sources from which chemical fertilizer is obtained may provide us with some insight. It is sometimes believed that the government, nongovernmental organizations (NGOs), and cooperatives generally provide good-quality chemical fertilizer, while fertilizer sourced from the private market is more likely to have quality issues. This may lead the government to decide to involve itself in the direct procurement of chemical fertilizer. However, fertilizer traders concerned with their own reputations may have an incentive to voluntarily keep the quality of their product high.

Table 3.9 summarizes the major sources of fertilizer for fertilizer-using households by agroecological belt, with all three rounds of the NLSS combined. Approximately 80 percent of fertilizer users obtained chemical fertilizer from the private market, while government, NGOs, and cooperatives accounted for approximately 3 to 6 percent each. The share breakdown in Table 3.9 is statistically significant across agroecological belts. A greater share of fertilizer-using households in the Terai get their fertilizer from the private market, compared with the Hills and Mountains, where the share of cooperatives is relatively higher than that in the Terai. Considering that the consumption of chemical fertilizer is growing the most in the Terai, the private market has been the major source of such growth.

Table 3.9 Shares of chemical fertilizer obtained from major sources by fertilizer-using households in each agroecological belt

\begin{tabular}{lrrrrr}
\hline $\begin{array}{l}\text { Type of } \\
\text { fertilizer }\end{array}$ & $\begin{array}{c}\text { Agroecological } \\
\text { belt }\end{array}$ & Government & NGO & Cooperative & Private market \\
\hline All chemical & Terai & 5.2 & 6.0 & 3.5 & 85.3 \\
fertilizer & Hills & 4.4 & 2.4 & 12.0 & 81.2 \\
& Mountains & 5.4 & 0.7 & 9.8 & 84.1 \\
\hline Urea & Terai & 5.2 & 6.0 & 3.2 & 85.6 \\
& Hills & 4.3 & 2.3 & 10.4 & 83.0 \\
& Mountains & 5.4 & 0.9 & 7.9 & 85.8 \\
\hline DAP & Terai & 4.9 & 6.5 & 3.3 & 85.2 \\
& Hills & 4.7 & 2.6 & 14.5 & 78.3 \\
& Mountains & 5.2 & 0.0 & 16.9 & 77.9 \\
\hline
\end{tabular}

Source: Authors' calculations based on the NLSS.

Note: The figures in the tables are at the end-user level. Therefore, if fertilizer was distributed through more than one channel, the last channel of distribution is counted. For example, some cooperatives receive fertilizer from the government, which is then distributed to farmers. Such a channel is counted under the cooperative, rather than the government, in the table. $\mathrm{NGO}=$ nongovernmental organization.

The private market's growing importance as a source of fertilizer suggests that the issue of fertilizer quality in that market may not be discouraging the demand for fertilizer there. However, could farmers be using more fertilizer of inferior quality in order to compensate for the quality by quantity? Though testing this empirically requires more thorough investigation, a simple conceptual framework suggests that in the standard setting, a lower quality of chemical fertilizer may rather discourage its use.

Suppose the production function is

$$
q=A(\theta * F)^{\beta},
$$

where $A$ is the total-factor productivity, $F$ is the quantity of fertilizer, and $\beta$ is the production coefficient. The parameter $\theta \in[0,1]$ is the quality indicator measuring the share of fertilizer weight that consists of actual fertilizer nutrients. 
Farmers' profit maximization problem is

$$
\pi=A(\theta * F)^{\beta}-p F,
$$

where $\pi$ is the profit and $p$ is the standardized price of fertilizer. Using the first-order condition, a profit-maximizing farmer will choose optimal fertilizer $F^{*}$ :

$$
F^{*}=\left(\frac{p}{\beta A}\right)^{\frac{1}{\beta-1}} \cdot \theta^{\frac{\beta}{1-\beta}}
$$

Since $\frac{\partial F^{*}}{\partial \theta}=\frac{\beta}{1-\beta} \cdot \frac{F^{*}}{\theta}>0$ as long as $0<\beta<1$, fertilizer consumption increases (decreases) as its quality improves (decreases).

Risk-averse farmers tend to use risk-reducing inputs more intensively and to use risk-increasing inputs less. Using this logic, if farmers are uncertain about the quality of fertilizer, they are more likely to substitute for fertilizer with other risk-reducing inputs.

In summary, under the standard setting, the following is more likely: if farmers are aware that the quality of fertilizer they are using is inferior, then they tend to use less, not more, quantity. Alternatively, if farmers perceive the quality to be uncertain, their risk-aversive nature will discourage, rather than encourage, use of fertilizer. Therefore, a convincing hypothesis is that fertilizer quality in the private market may not be a constraint for fertilizer use in Nepal. However, such a hypothesis must be carefully examined in future studies.

\section{Access to Fertilizer}

The information is limited regarding how access to chemical fertilizer is constrained. The NLSS 2010 asks chemical-fertilizer-using households whether they could obtain the desired amount. In 2010, about 90 percent of households using fertilizer said yes (Table 3.10), indicating that where fertilizer is supplied, availability may be generally high. However, the NLSS does not report whether households wanted to use fertilizer but could not obtain it. As the share of those not using fertilizer is still relatively high, particularly in the Hills and the Mountains (40 to 50 percent in 2010 in Table 3.3, as opposed to 20 percent in the Terai), future studies must investigate whether access to fertilizer is significantly constraining those households.

Table 3.10 Percentage of fertilizer users who could use desired amount of fertilizer

\begin{tabular}{ll}
\hline Zone & $\mathbf{2 0 1 0}$ \\
\hline Terai & $91 \pm 1$ \\
Hills & $90 \pm 2$ \\
Mountains & $90 \pm 5$ \\
All & $91 \pm 1$ \\
\hline
\end{tabular}

Source: Authors' calculation based on the NLSS.

Note: The NLSS asks only fertilizer users whether they obtained the desired amount.

\section{Relatively Minor Use of Credit for Agricultural Input Purchases}

The pattern of credit use provides insight into the role of agricultural finance in fertilizer use. For farm households in Nepal, the largest source of credit is the informal sector, such as relatives and shopkeepers/moneylenders (Table 3.11). Moreover, the credit is typically used for household consumption needs, some personal uses, or family- and household-related needs, and it is rarely used for the purchase of agricultural inputs (Tables 3.12 and 3.13). While that does not mean the role of agricultural finance may be limited for increasing fertilizer use (because a majority of households obtaining credit in these tables may be engaged more in off-farm activities), it suggests some challenges 
in increasing fertilizer use through agricultural finance programs. The empirical analysis in the later sections confirms that the effect of credit access on chemical fertilizer use is relatively limited in Nepal.

Table 3.11 Farm households obtaining credit and average credit amount by source

\begin{tabular}{lcc}
\hline Source & $\begin{array}{c}\text { Share (\%) of farm } \\
\text { households taking credit } \\
\text { from this source }\end{array}$ & $\begin{array}{c}\text { Average amount including those } \\
\text { without credit (equivalent to } \\
\text { kilograms of cereals) }\end{array}$ \\
\hline Relatives & 26 & 848 \\
Agricultural development bank & 2 & 159 \\
Commercial bank & 0 & 53 \\
Grameen-type bank & 1 & 56 \\
Other financial institution & 8 & 312 \\
Nongovernmental org./relief agency & 3 & 47 \\
Landlord/employee & 1 & 19 \\
Shopkeeper/moneylender & 8 & 281 \\
Cooperative & 4 & 91 \\
Other & 3 & 36 \\
\hline
\end{tabular}

Source: Authors' calculations based on the NLSS.

Table 3.12 Farm households obtaining credit for different purposes in 2010

\begin{tabular}{lcr}
\hline Purpose & $\begin{array}{c}\text { Share (\%) of farm } \\
\text { households taking credit } \\
\text { for particular purposes }\end{array}$ & $\begin{array}{c}\text { Average amount including those } \\
\text { without credit (equivalent to } \\
\text { kilograms of cereals) }\end{array}$ \\
\hline Agricultural inputs & 2 & 30 \\
Agricultural equipment & 0 & 23 \\
Purchase of land & 3 & 259 \\
Purchase of livestock & 4 & 61 \\
Building materials & 0 & 20 \\
Other business or farm use & 6 & 393 \\
Household consumption needs & 21 & 333 \\
Purchase or improve dwelling & 5 & 324 \\
Management/family events & 5 & 200 \\
Consumer durables & 1 & 44 \\
Other personal use & 9 & 212 \\
\hline
\end{tabular}

Source: Authors' calculations based on the NLSS.

Table 3.13 Percentage of farm households obtaining credit

\begin{tabular}{|c|c|c|c|c|c|c|c|}
\hline \multirow[t]{2}{*}{ Belt } & \multirow[t]{2}{*}{ Type of farm household } & \multicolumn{3}{|c|}{$\begin{array}{c}\% \text { using credit for the } \\
\text { purchase of } \\
\text { agricultural inputs }\end{array}$} & \multicolumn{3}{|c|}{$\begin{array}{l}\text { \% using credit for any } \\
\text { purposes (mostly } \\
\text { consumption needs) }\end{array}$} \\
\hline & & 1995 & $\begin{array}{l}2002 / \\
2003\end{array}$ & $\begin{array}{c}2009 / \\
2010\end{array}$ & 1995 & $\begin{array}{l}2002 / \\
2003\end{array}$ & $\begin{array}{l}2009 / \\
2010\end{array}$ \\
\hline \multirow[t]{3}{*}{ Terai } & Fertilizer users & 7 & 4 & 4 & 54 & 59 & 48 \\
\hline & Fertilizer users (desired quantity) & 7 & 4 & 4 & 55 & 58 & 47 \\
\hline & Nonuser & 1 & 0 & 1 & 46 & 59 & 49 \\
\hline \multirow[t]{3}{*}{ Hills } & Fertilizer users & 2 & 3 & 2 & 49 & 56 & 52 \\
\hline & Fertilizer users (desired quantity) & 2 & 3 & 1 & 47 & 57 & 51 \\
\hline & Nonuser & 0 & 1 & 1 & 47 & 55 & 44 \\
\hline \multirow[t]{3}{*}{ Mountains } & Fertilizer users & 5 & 7 & 3 & 56 & 66 & 50 \\
\hline & Fertilizer users (desired quantity) & 6 & 7 & 2 & 56 & 66 & 49 \\
\hline & Nonuser & 1 & 0 & 0 & 48 & 45 & 49 \\
\hline
\end{tabular}

Source: Authors' calculations based on the NLSS.

Note: The figures are based on farm households that obtained credit in 1995, 2002 or 2003, and 2009 or 2010, respectively. 


\section{PRICE RESPONSES AND MARGINAL VALUE PRODUCTS OF CHEMICAL FERTILIZER USE: EMPIRICAL METHODS}

The descriptive analysis in the previous sections provides the impression that the low chemical fertilizer use in the Hills and the Mountains is due to its higher price caused by higher transportation costs. It is, however, also possible that the marginal returns to intensive chemical fertilizer use are inherently low in these regions, which leads to its lower use even at the same fertilizer price, and a smaller increase in its use when prices are lowered through subsidies. Here, we assess this hypothesis by investigating the price responses and marginal returns of chemical fertilizer and and how they vary across agroecological belts.

\section{Methodology for Assessing the Price Response of Chemical Fertilizer Use}

The price responses of chemical fertilizer use we estimate are in a reduced form, which combine both demand and supply factors. They are therefore equilibrium price responses rather than price responses derived from the demand function in a strict sense. However, under the reasonable assumption that the fertilizer market is fairly competitive and individual farmers are price takers, the equilibrium price responses estimated from the farm household data largely correspond to those derived from the demand function. ${ }^{6}$ We use the Tobit model to account for the corner-solution nature of fertilizer use, as a significant fraction of households in the sample report zero quantity used. As in Takeshima and Nkonya (2014), the model incorporates pseudo-panel correlated random effects, which exploits the availability of three rounds of the NLSS, from which we can construct a pseudo-panel with appropriate cohorts. ${ }^{7}$

Price responses are estimated controlling for many other potential determinants of chemical fertilizer use. The other determinants largely consist of (1) agroecological conditions; (2) socioeconomic conditions; and (3) indicators of varietal technology levels that affect the marginal physical productivity of the chemical fertilizer. Agroecological conditions include soil type, rainfall (historical average and standard deviation), solar radiation, terrain ruggedness, elevation, and agricultural area per capita in village development committees (VDCs). ${ }^{8}$ Socioeconomic conditions include household manure endowment, household size, gender and literacy level of the head, average education level of workingage household members, costs of other inputs like labor (real wages) and tractor services (tractor rental cost per hour), credit access (indicated by the credit taking in previous years), size of own farmland (lowland and upland, respectively), number of owned plots, asset holdings (farmland, livestock, farm equipment, and the rest), whether owning draft animals or not, market access, factors affecting shadow wage of family member, and ethnic background.

Earlier studies suggest that the shadow wage of family labor also affects the demand for labor (Jacoby 1993) and thus complementary inputs like fertilizer. Jacoby points out that the shadow wage of family labor (particularly of female) can be particularly affected by whether piped water is the main source of drinking water for the household, whether the household owns the house, whether electricity is the main source of light, and whether wood is the main source of cooking fuel. ${ }^{9}$ We therefore include dummy variables indicating these.

Indicators of varietal technology levels include various technological distance indicators, such as the Euclidean distance from an Agriculture Research Station (ARS), the Euclidean distance from the Indian border, and the similarity of soil and rainfall risk conditions to those where the ARS is located.

\footnotetext{
${ }^{6}$ This is particularly so for chemical fertilizer, whose supply elasticity of price is generally very high. For example, Quizón and Binswanger (1986) consider the supply elasticity to be as high as 4.0 for India.

${ }^{7} \mathrm{We}$ also estimated a multivariate Tobit model using the mvtobit command in Stata where error terms in the urea equation and the DAP equation are correlated, and we found that results are quite similar when the regression for each type of fertilizer is run independently.

${ }^{8}$ The VDC is an administrative unit in Nepal, placed under the district. There are approximately 3,600 VDCs, although that number varies from time to time.

${ }^{9}$ While Jacoby (1993) also uses an indicator of whether the household has access to garbage disposal service, we exclude it in our analysis because very few farm households in our sample have such access.
} 
We use both the Euclidean distance from an ARS and the similarity of certain climatic conditions and soil types in the analysis to control for the technological distances, which are considered important in determining the varietal technology levels (Evenson and Westphal 1995), and thus potential fertilizer responses of crops.

Lastly, dummy variables are included to control for sector (urban or rural), agroecological belt (Terai or other regions), administrative zone (five development regions), and year-specific effects. While most variables are from the NLSS, some have been compiled from other sources. We describe later in more detail how the variables have been constructed in our analysis.

\section{Locations of Agriculture Research Stations}

Nepal conducts plant-breeding activities at various locations across the country. Although it cross-breeds new varieties of major crops mainly at designated headquarters of the Nepal Agricultural Research Council or the national crop research programs, some developed varieties as well as foreign varieties of certain crops go through field evaluations at the research stations that often focus on other crops. Some university departments are also involved with plant breeding, although the extent of their activities is not clear. Table 4.1 summarizes the types of programs and institutions that are mainly leading the plant breeding, while Figure 4.1 illustrates the geographic distribution of these institutions.

Table 4.1 Key Nepali Agriculture Research Stations used in the model

\begin{tabular}{ll}
\hline Type & Institution \\
\hline Nepal Agricultural Research & Eastern Development Region \\
Council & Central Development Region \\
& Western Development Region \\
& Mid-Western Development Region \\
& Far-Western Development Region \\
\hline National research programs & Rice, wheat, maize, grain, legumes, oilseeds, sugarcane, citrus, potato, jute, \\
(crops and livestock) & ginger, hill crops, bovine, sheep and goat, swine and avian \\
\hline & Department of Plant Breeding, Institute of Agriculture and Animal Science \\
Universities & (under Tribhuvan University), \\
& Kathmandu University, School of Science, Department of Biotechnology, \\
& Purbanchal University, \\
& Pokhara University \\
\hline
\end{tabular}

Source: Authors' compilations based on Nepal Agricultural Research Council and secondary sources.

Figure 4.1 Locations of Agriculture Research Stations and major universities with breeding activities

Source: Authors' compilations from various sources.

Note: Black dots indicate Agriculture Research Stations and key universities with plant-breeding activities, while gray dots are centroids of village development committees in Nepal. 


\section{Agroecological Data}

Various sets of spatial data of agroecological conditions are obtained. Historical monthly rainfall data between 1970 and 2000 are in 0.5 -by-0.5-degree grids (http://csi.cgiar.org/cru/SELECTION/inputCoord.asp). From this, we calculated the historical average and standard deviation of rainfall in each month in each VDC. We first identified which grid each VDC belongs to and applied the values in the grid to the VDC. If a VDC straddles multiple grids, the grid that overlaps the largest area of the VDC was chosen.

Monthly solar radiation data are for the years 2000, 2002, and 2003 in 10-kilometer grids, from Deutsches Zentrum für Luft- und Raumfahrt, or DLR (2004) (http://en.openei.org/datasets/dataset/solarmonthly-and-annual-average-global-horizontal-ghi-gis-data-at-10km-resolution-for-nepal-from).

Soil data are from FAO et al. (2012). The dominant soil type in each VDC is the soil that covers the largest area within the VDC.

Terrain ruggedness and elevations are based on GTOP30 data (U.S. Geological Survey 1996).

Ruggedness is calculated following Riley, DeGloria, and Elliot (1999) and has been used in recent studies (Nunn and Puga 2012). The median values within the VDCs are used.

Endowments of cultivable land are the sum of cropped areas and pasture (Ramankutty et al. 2008), as pasture is relatively easily converted into farmland compared with forest (Binswanger and Donovan 1987). This figure was divided by the population of the corresponding VDC interpolated from the population censuses of 1991, 2001, and 2011 in order to obtain cultivable land area per capita.

\section{Variables Potentially Associated with Manure Use}

The quantities of manure used are not reported in the NLSS data, and we have to rely on the best estimates of typical manure use given the livestock holding, as discussed earlier. We complement this by including key variables that are expected to affect manure use. The assumption is that these variables affect inorganic fertilizer use either directly or indirectly through the use of manure. Some of the identified variables are lower caste status, livestock ownership, and lower land quality (Aryal and Holden 2013) and smaller plot size (Gao, Huang, and Rozelle 2012). Land quality is proxied here by whether the plot is lowland (relatively better quality) or upland, while the plot size effect is captured by the number of plots given the total area of farmland owned. The variable terrain ruggedness of a VDC can also broadly proxy for the terrain of plots, as manure tends to be used more on plots with less flat terrain (Gao, Huang, and Rozelle 2012).

\section{Sample Size}

Our analysis of the determinants of chemical fertilizer use is based on the cross-sectional sample as well as the panel sample in 2003 in order to make use of the maximum possible information. We also adjusted for the sample weights for the cross-sectional sample and the 2003 panel sample, which were provided by the Nepali Central Bureau of Statistics, to obtain representative estimates. ${ }^{10}$ The 2010 panel sample was excluded because the Central Bureau did not provide sample weights.

The primary sample consisted of 9,648 households that reported cultivating their own farms in all three rounds of the NLSS and for whom sample weights were provided. From that sample, those that were missing key information like time to market center, educational status, or other observations were dropped. In certain cases, household locations could not be identified because the VDC they belonged to was unidentified. Consequently, a total of 7,648 observations were used for the analysis.

Table 4.2 summarizes the descriptive statistics of these variables.

\footnotetext{
${ }^{10}$ It is known that the calculation of sample weights for panel households is somewhat complicated, and future studies will have to investigate how they may affect the results. For our study, we also conducted an analysis excluding the 2003 panel households, and we found that the key findings were qualitatively similar.
} 
Table 4.2 Descriptive statistics (all years combined)

\begin{tabular}{|c|c|c|}
\hline Variable & Mean & S.E. \\
\hline Price of urea per kilogram (kg of cereals) ${ }^{a}$ & 1.52 & .60 \\
\hline Price of DAP per kilogram (kg of cereals) & 2.35 & .64 \\
\hline Soil $=$ Humic Acrisols (Ah) (default) & .04 & .21 \\
\hline Soil $=$ Dystric Cambisols $(\mathrm{Bd})$ & .53 & .50 \\
\hline Soil = Eutric Fluvisols (Je) & .35 & .47 \\
\hline Soil = Dystric Regosols (Rd) & .08 & .27 \\
\hline Soil $=$ minor soil & .00 & .05 \\
\hline Rainfall (historical average) & 1371.72 & 260.46 \\
\hline Rainfall (historical standard deviation) & 589.56 & 91.15 \\
\hline Solar radiation index & 4432.20 & 388.80 \\
\hline Terrain ruggedness index & 293.59 & 267.80 \\
\hline Elevation (meter, VDC median) & 848.59 & 807.11 \\
\hline Per capita agricultural area (crop area + pasture area) (hectares per capita) & .20 & .33 \\
\hline Fertilizer manure endowments $(\mathrm{kg})$ & 52.56 & 44.19 \\
\hline Household size & 5.75 & 2.76 \\
\hline Gender of household head $(1=$ male, $0=$ female $)$ & .81 & .39 \\
\hline Literacy of household head ( $1=$ literate, $0=$ illiterate) & .48 & .50 \\
\hline Average education levels of working-age household members & 3.07 & 2.96 \\
\hline Real wage (daily wage, $\mathrm{kg}$ of cereal) & 10.72 & 3.48 \\
\hline Tractor rental cost per hour ( $\mathrm{kg}$ of cereal) & 44.34 & 11.84 \\
\hline Irrigation (share of farm households irrigating within the VDC) & .57 & .14 \\
\hline Whether obtained credit in the previous year (yes $=1$ ) & .32 & .47 \\
\hline Whether obtained formal credit in the previous year (yes $=1$ ) & .06 & .24 \\
\hline Land area owned (lowland, hectares) & .44 & .92 \\
\hline Land area owned (upland, hectares) & .34 & .80 \\
\hline Number of plots & 3.51 & 2.93 \\
\hline Real household asset value-excluding farmland, livestock, equipment (kg of cereals) & 27810.71 & 103059.4 \\
\hline Real household asset value_farmland ( $\mathrm{kg}$ of cereals) & 62948.80 & 338897.4 \\
\hline Real household asset value-livestock (kg of cereals) & 2289.18 & 2012.21 \\
\hline Real household asset value_equipment (kg of cereals) & 505.25 & 3949.32 \\
\hline Ownership of draft animals (bullock/cow, buffalo, horse/donkey/mule) & .64 & .48 \\
\hline Time to the market center (minutes) ${ }^{b}$ & 80.00 & 1418.58 \\
\hline$\%$ of advanced caste in VDC ${ }^{c}$ & .06 & .11 \\
\hline$\%$ of nonindigenous population in VDC ${ }^{\mathrm{C}}$ & .31 & .21 \\
\hline Piped water as main source of drinking water $(1=$ yes $)$ & .40 & .49 \\
\hline Own house $(1=$ yes $)$ & .98 & .15 \\
\hline Electricity the main source of light $(1=$ yes $)$ & .36 & .48 \\
\hline Wood the main source of cooking fuel ( $1=$ yes) & .75 & .43 \\
\hline Sector (urban $=0$, rural $=1$ ) & .02 & .24 \\
\hline Euclidean distance from Indian border (Terai only) (geographical minutes) & .05 & .08 \\
\hline Euclidean distance from Ag Research Station border (geographical minutes) (Figure 4.1) & .32 & .24 \\
\hline Soil similarity with Agriculture Research Station & .84 & .37 \\
\hline Difference in standard deviation of rain & 14.55 & 24.07 \\
\hline Real annual household earned income (measured in $\mathrm{kg}$ of cereals) & 14156.25 & 19744.53 \\
\hline
\end{tabular}

Source: Authors.

Note: $\quad{ }^{a}$ All monetary values are measured in kilograms $(\mathrm{kg})$ of cereals in each year, converted by the local cereals price. ${ }^{\mathrm{b}}$ Time to market center is shown in median due to the highly skewed distribution. ${ }^{\mathrm{c}}$ Advanced caste is defined as Newar or Thakali, while nonindigenous population is defined as Chhetri, Brahman (Hills), or Brahman (Terai) based on Gellner (2007). 


\section{Methodologies for Assessing Gross Returns to Chemical Fertilizer Use}

The NLSS data contain information that allows us to estimate household income together with chemical fertilizer use and various socioeconomic characteristics. One way to assess the returns to chemical fertilizer use is to assess how the quantity of chemical fertilizer use affects household income, conditional on various household characteristics. Estimation is challenging if the returns to chemical fertilizer are nonlinear in the quantity of chemical fertilizer used. The estimation is also complicated due to potential endogeneity; for example, while fertilizer use may affect household income, household income may also affect fertilizer use. When using a popular method such as two-stage least squares, proper instrumental variables are needed to account for the endogeneity of fertilizer; however, such instrumental variables may not be readily available.

Instrumental variables are not needed if one assumes that the quantity of fertilizer is a deterministic function of observable characteristics and that, conditional on observable characteristics, incomes and quantity of fertilizer used are independent. This is an extension of the unconfoundedness assumption employed in propensity score matching (PSM) to a continuous treatment case. Under this assumption, both PSM and generalized propensity score matching (GPSM) can be used to assess the impact of chemical fertilizer use (at both the extensive margin and the intensive margin). While PSM and GPSM are conventionally used for program impact evaluation, a growing number of studies apply these methods to assess the impact of farmers' decisions other than in program participation, such as for technology adoption (Takeshima 2015a) and market participation (Takeshima and Nagarajan 2012).

The literature also often estimates the value-cost ratio (VCR). We, however, do not estimate the VCR for several reasons. A practical reason is that the data do not allow for a precise VCR estimate, because chemical fertilizer use is not recorded at the plot level or at the crop level. Nor is the use of other inputs, such as labor, recorded at such an aggregated level.

However, more importantly, calculations of the VCR often do not account for heterogeneity at different levels of fertilizer use, even though it can vary in reality. In addition, calculations of the VCR are often conditional on other activities being fixed, such as noncrop production or nonfarm activities. But in reality, chemical fertilizer use can affect the use of other inputs, labor, and therefore off-farm income earnings. If these effects are significant relative to the effects on crop production, they affect the overall returns to chemical fertilizer, and must be captured. While we are not interested in each of these effects or their impact pathways, and estimating them individually is often challenging because NLSS data are not precise enough in these aspects, the NLSS allows estimations of overall income effects, which we are interested in. NLSS data also cover households with varying levels of chemical fertilizer use, and that allows us to estimate the income effects of chemical fertilizer at different intensity levels. To explore such data, however, appropriate estimators are needed. GPSM is one such method.

\section{Generalized Propensity Score Matching}

GPSM is an extension of the well-known PSM method to the case of continuous treatment. Application of GPSM to our context assumes that the quantity of chemical fertilizer used is a deterministic function of observable characteristics and that, conditional on observable characteristics, incomes and fertilizer quantity are independent (unconfoundedness assumption). This allows us to attribute income changes to chemical fertilizer use.

GPSM involves estimating generalized propensity scores (GPSs) from the estimated conditional density of treatment, and using the scores to find suitable matches. Using these matches, treatment effects are estimated at different levels of treatment, which leads to the "dose-response function." The dose-response function informs whether treatment effects vary with treatment intensity, upon receiving the treatment.

GPSM is built on the following framework (Hirano and Imbens 2004; Bia and Mattei 2008). Each random sample $i=1, \ldots, N$ is associated with a set of potential outcomes $\Pi_{i}(t)$, conditional on treatment $t \in T$ (referred to as the unit-level dose-response function). Our interest is in the average doseresponse function across $i, \mu(t)=E\left[\Pi_{i}(t)\right]$. Each $i$ is also associated with observed covariates $X_{i}$, 
treatment $T_{i} \in\left[t_{0}, t_{1}\right]$ where $t_{0}$ and $t_{1}$ are the lower and upper bounds of treatment level, and observed outcome $\Pi_{i}\left(T_{i}\right)$. The weak unconfoundedness condition of GPSM is $\Pi(t) \perp T \mid X$ for all $t \in T$ (subscript $i$ is dropped for simplicity).

We denote $r(t, x)$ as the conditional density of the treatment $t$ given the covariates $x, r(t, x)=$ $f_{T \mid X}(t \mid x)$, and the specific GPS as $R=r(T, X)$. The GPS assumes that within strata with the same $r(t, x)$, the probability that $T=t$ does not depend on $x$. Tests have been developed to check the balancing property in the case of GPSM as in PSM (Bia and Mattei 2008).

GPSM consists of three steps. First, $T_{i}$ or its certain transformation $g\left(T_{i}\right)$ is regressed on $X$ through the maximum likelihood method with normally distributed disturbance term, calculating $\hat{R}_{i}=$ $\frac{1}{\sqrt{2 \pi \widehat{\sigma}^{2}}} \exp \left[-\frac{1}{2 \widehat{\sigma}^{2}}\left\{g\left(T_{i}\right)-h\left(\hat{\gamma}, X_{i}\right)\right\}\right]$. Second, conditional expectations of the outcome $\Pi(t)$ are estimated as polynomial functions of $T$ and $\hat{R}$ through ordinary least squares. ${ }^{11}$ Third, the dose-response function is obtained by connecting across $t$ the $E\{\widehat{\Pi(t)}\}$, the sample average of predicted $\Pi(t)$ obtained from the second-stage regression above. We estimate $E\{\widehat{\Pi(t)}\}$ and the 90 percent confidence intervals for sample deciles of $t$ and plot them, where confidence intervals are estimated by 200 bootstrap processes that take into account the fact that various parameters including the GPSs are estimated values. $^{12}$

\section{Household Classifications Combined with GPSM}

The validity of GPSM rests on having matched samples with similar exogenous characteristics. Conditioning of the GPS partly achieves that, but one can also improve the matching properties by limiting the analysis to more homogeneous subgroups. Table 4.3 summarizes four subgroups of farm households in each of the Terai and Hills zones, as well as their representativeness measured as shares of chemical fertilizer used. For the Hills zone, the central region is excluded because the much higher level of fertilizer use there, as shown in Table 3.3, indicates that the production characteristics may be quite different from those of the rest of the Hills zone. Since soil type is an important determinant of farming systems and returns to fertilizer, the estimation is limited to the sample within the areas covered by dominant soils-Eutric Fluvisols in the Terai and Dystric Cambisols in the Hills (FAO et al. 2012). Four subgroups are defined based on the sample median of two key farm household characteristics: farm size and household assets. The balancing properties, as described in the results section, are satisfied based on these classifications, indicating that household characteristics do not differ significantly conditional on the estimated GPS within each subgroup. Among medium-to-large-scale households in the Terai (own land size of at least 0.5 hectare), those owning more than 1.5 hectares of farmland are excluded because their characteristics are quite different from the rest of the medium-to-large-scale households and violate the balancing properties.

As Table 4.3 shows, the identified subgroups account for two-thirds of farm households using chemical fertilizer and at least half of the quantity of chemical fertilizer used in the Terai, and at least three-quarters of households using chemical fertilizer and of the quantity used for the Hills excluding the central zone. The analysis based on these subgroups, therefore, has important implications for the returns to fertilizer for the whole of each zone.

\footnotetext{
${ }^{11}$ No clear criteria exist regarding polynomial specifications. Generally, higher-order polynomials and interaction terms of $T$ and $\hat{R}$ capture more complex income effects of chemical fertilizer quantities, but estimates are inefficient, while the parsimonious specification is restrictive but efficient. We select the following two specifications: (a) up to the third polynomials of $T$ and linear $\hat{R}$; and (b) linear $T$ and linear $\hat{R}$, without interaction of $T$ and $\hat{R}$ in both specifications. Specification (a) is selected because the third polynomials of $T$ are found statistically significant across many subgroups of samples described below, while only linear $\widehat{R}$ is generally statistically significant. Specification (b) is selected as well, to see if results from (a) are robust under parsimonious but efficient specification.

${ }^{12}$ GPSM is run using the Stata command doseresponse (Bia and Mattei 2008). Bia and Mattei rely on the normality assumption of the conditional density of $t($ or $g(t))$. In our case, normality assumptions are satisfied at the 5 percent statistical significance level when function $g$ is a natural $\log$, so that the estimated dose-response functions are consistent using $\ln (t)$ in place of $t$.
} 
Table 4.3 Subgroups of farm households defined for assessing returns to chemical fertilizer use (among farm households using chemical fertilizer)

\begin{tabular}{|c|c|c|c|c|c|c|c|c|c|}
\hline \multicolumn{5}{|c|}{ Terai (soil = Eutric Fluvisols) } & \multicolumn{5}{|c|}{$\begin{array}{l}\text { Hills excluding the central region } \\
\text { (soil = Dystric Cambisols) }\end{array}$} \\
\hline \multicolumn{2}{|c|}{ Type } & \multirow{2}{*}{$\begin{array}{l}\text { Cultivated } \\
\text { area per year* }\end{array}$} & \multirow{2}{*}{$\begin{array}{l}\text { Share (\%) } \\
\text { of farm } \\
\text { households }\end{array}$} & \multirow{2}{*}{$\begin{array}{l}\text { Share (\%) } \\
\text { of fertilizer } \\
\text { use }\end{array}$} & \multicolumn{2}{|c|}{ Type } & \multirow{2}{*}{$\begin{array}{l}\text { Cultivated area } \\
\text { per year * }\end{array}$} & \multirow{2}{*}{$\begin{array}{l}\text { Share (\%) } \\
\text { of farm } \\
\text { households }\end{array}$} & \multirow{2}{*}{$\begin{array}{l}\text { Share (\%) } \\
\text { of fertilizer } \\
\text { use }\end{array}$} \\
\hline $\begin{array}{l}\text { Own land } \\
\text { size (ha) }\end{array}$ & 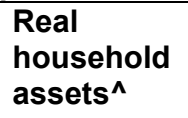 & & & & $\begin{array}{l}\text { Own land } \\
\text { size (ha) }\end{array}$ & $\begin{array}{l}\text { Real } \\
\text { household } \\
\text { assests^ }^{\wedge}\end{array}$ & & & \\
\hline$<0.5$ & $<25,000$ & $0.6 / 0.9$ & 20 & 8 & $<0.5$ & $<30,000$ & $0.5 / 0.7$ & 23 & 13 \\
\hline$<0.5$ & $\geq 25,000$ & $0.7 / 0.9$ & 17 & 11 & $<0.5$ & $\geq 30,000$ & $0.5 / 0.6$ & 17 & 14 \\
\hline $0.5 \sim 5.0$ & $<75,000$ & $1.8 / 2.3$ & 15 & 15 & $>0.5$ & $<50,000$ & $1.4 / 1.9$ & 23 & 22 \\
\hline $0.5 \sim 1.5$ & $\geq 75,000$ & $2.0 / 2.0$ & 12 & 17 & $>0.5$ & $\geq 50,000$ & $1.5 / 1.9$ & 19 & 26 \\
\hline Total & & & 64 & 51 & & & & 82 & 75 \\
\hline
\end{tabular}

Source: Authors.

Note: $\quad$ ha $=$ hectares; $\mathrm{kg}=$ kilograms. ${ }^{\wedge} \mathrm{kg}$ of cereals; ${ }^{*}$ ha, median $/$ mean. 
Importantly, total cultivated areas are relatively comparable between the Terai and the Hills excluding the central region. Among the larger-scale, higher-asset households specified, the median cultivated area in the Terai is 2.0 hectares, only about 33 percent higher than the median in the Hills excluding the central region. In terms of the mean, the figure in the Terai is only 5 percent higher than that in the Hills excluding the central region (2.0 versus 1.9$)$. While the differences are slightly larger in the other subgroups, they are not greater than 50 percent. These are important when interpreting the estimated income effects described in the next section.

\section{Household Income}

Household income is measured by the aggregate annual household expenditure, which is often a more accurate estimate of actual income than reported income (Deaton 1997). It is the total of annual household expenditure on nondurables (food and nonfood), annual educational expenses (for example, school fees), health expenses, net purchase of agricultural equipment, expenditures on utilities (water, gas, electricity, firewood), net rent payment of the housing (= rent paid for housing rented in minus rent received for housing rented out), net credit lending, net asset rent paid (= rent paid for assets rented in minus rent received for assets rented out), and net remittances sent.

The value of food consumption is assessed from the quantities consumed multiplied by the market purchase prices (household specific or district median). The reported food consumption in the NLSS is for seven days prior to the interview. Therefore, the amount was multiplied by $365 / 7$ to obtain the annual amount. Similarly, expenditures on all the other items are converted into annual figures whenever necessary. Real expenditure value is measured as kilograms of cereals, based on average local prices of rice and wheat.

\section{Samples Used for the Analysis of Gross Returns to Chemical Fertilizer}

For this analysis, we use the same sample set described earlier, except that we exclude the 2003 panel of households. This is because the literature is not clear about how to treat panel households in the GPSM context. 


\section{DEMAND FOR INORGANIC FERTILIZER: EMPIRICAL RESULTS}

We now provide empirical evidence of fertilizer use in Nepal. Key hypotheses are that major variations in fertilizer use are partly due to the returns to that use, rather than simply variations in fertilizer price. Using the three rounds of NLSS data described earlier, we assess the determinants of chemical fertilizer use. In particular, we show that chemical fertilizer use is less price responsive in the Hills and the Mountains than in the Terai. We also show that this is consistent with the lower returns to chemical fertilizer in the Hills outside the central region, compared with those in the Terai.

\section{Determinants of Chemical Fertilizer Use and Price Responses}

Table 5.1 summarizes the determinants of chemical fertilizer use, both absolute quantities per household and quantities per cultivated area. Figures are marginal effects evaluated at the means of other covariates. Regressions are adjusted for the probability weights of the sample, so that the estimates consistently represent the behaviors of all the population. Standard errors of coefficients are estimated taking into account the serial correlation of idiosyncratic shocks within the enumeration areas, as agricultural production is often subject to unobserved agroecological shocks such as weather or pests, which tend to be correlated within the small geographical area. ${ }^{13}$

Table 5.1 Determinants of chemical fertilizer use, pseudo-panel, correlated random-effects Tobit (marginal effects evaluated at the means of covariates)

\begin{tabular}{|c|c|c|c|c|c|}
\hline Explanatory variable & $\begin{array}{l}\text { Quantity of } \\
\text { urea used } \\
\text { per year } \\
\text { (kg) }\end{array}$ & $\begin{array}{l}\text { Quantity of } \\
\text { DAP used } \\
\text { per year } \\
(\mathbf{k g})\end{array}$ & $\begin{array}{l}\text { Urea used per } \\
\text { cultivated area } \\
\text { per year } \\
\text { (kg/ha) }\end{array}$ & $\begin{array}{l}\text { DAP used per } \\
\text { cultivated area } \\
\text { per year } \\
\text { (kg/ha) }\end{array}$ & $\begin{array}{c}\text { Chemical } \\
\text { fertilizer } \\
\text { nutrients per } \\
\text { cultivated area } \\
\text { per year (kg/ha) }\end{array}$ \\
\hline In(price of Urea) & $-25.244^{* *}$ & 6.997 & .358 & $7.158^{*}$ & \\
\hline $\ln ($ price of DAP $)$ & -5.131 & $-33.305^{\star * *}$ & -.777 & $-29.041^{\star * *}$ & \\
\hline In(average price) & & & & & -19.674 \\
\hline $\begin{array}{l}\text { In(price of Urea)*dummy (Hills \& } \\
\text { Mountains) }\end{array}$ & $22.999^{* * *}$ & & $18.367^{*}$ & & \\
\hline $\begin{array}{l}\text { In(price of DAP)*dummy (Hills \& } \\
\text { Mountains) }\end{array}$ & & 11.646 & & .971 & \\
\hline $\begin{array}{l}\text { In(average price)*dummy (Hills \& } \\
\text { Mountains) }\end{array}$ & & & & & 13.026 \\
\hline In(price)*year 2003 dummy & -4.037 & 13.414 & -28.667 & 16.082 & 12.334 \\
\hline In(price) $)^{*}$ year 2010 dummy & -19.049 & -16.289 & $-23.830^{* *}$ & -1.848 & -14.728 \\
\hline Rainfall (historical average, $\mathrm{mm}$ ) & -.109 & -.195 & -.085 & -.033 & $-.207^{*}$ \\
\hline $\begin{array}{l}\text { Rainfall (historical standard deviation, } \\
\mathrm{mm} \text { ) }\end{array}$ & $1.695^{* * *}$ & $.885^{\star * *}$ & $1.286^{\star * *}$ & .335 & $1.206^{* * *}$ \\
\hline $\begin{array}{l}\text { Average solar radiation (annual average, } \\
2000,2002 \text {, and 2003) }\end{array}$ & $-.014^{*}$ & $-.012^{*}$ & -.011 & -.009 & $-.013^{\star *}$ \\
\hline Terrain ruggedness index & $-.059^{* * *}$ & $-.041^{* * *}$ & $-.063^{* * *}$ & $-.035^{\star * *}$ & $-.050^{* * *}$ \\
\hline Elevation (VDC median, meter) & -.005 & -.004 & -.009 & -.003 & -.006 \\
\hline $\begin{array}{l}\text { Agricultural area per capita in VDC } \\
\text { (index) }\end{array}$ & 13.143 & 2.349 & 5.188 & -.072 & $9.388^{*}$ \\
\hline Manure nutrients $(\mathrm{kg})$ & $-.168^{*}$ & $-.130^{*}$ & .035 & $-.077^{\star *}$ & -.052 \\
\hline $\begin{array}{l}\text { Manure nutrients }(\mathrm{kg})^{*} \text { dummy (Hills \& } \\
\text { Mountains }=1 \text { ) }\end{array}$ & .136 & .072 & $-.311^{* * *}$ & .012 & $.123^{*}$ \\
\hline Household size & $1.411^{* * *}$ & -.035 & -.090 & -.243 & -.251 \\
\hline $\begin{array}{l}\text { Gender of household head }(1=\text { male, } 0= \\
\text { female) }\end{array}$ & $5.135^{\star * *}$ & 1.863 & 3.385 & .442 & 1.539 \\
\hline
\end{tabular}

${ }^{13}$ Under general regularity conditions, the Tobit model estimates are often consistent, although inefficient, in the presence of serially correlated error terms (Robinson 1982). 
Table 5.1 Continued

\begin{tabular}{|c|c|c|c|c|c|}
\hline Explanatory variable & $\begin{array}{l}\text { Quantity } \\
\text { of urea } \\
\text { used per } \\
\text { year (kg) }\end{array}$ & $\begin{array}{l}\text { Quantity of } \\
\text { DAP used } \\
\text { per year } \\
(\mathbf{k g})\end{array}$ & $\begin{array}{l}\text { Urea used per } \\
\text { cultivated area } \\
\text { per year } \\
\text { (kg/ha) }\end{array}$ & $\begin{array}{l}\text { DAP used per } \\
\text { cultivated area } \\
\text { per year } \\
\text { (kg/ha) }\end{array}$ & $\begin{array}{c}\text { Chemical } \\
\text { fertilizer } \\
\text { nutrients per } \\
\text { cultivated area } \\
\text { per year (kg/ha) }\end{array}$ \\
\hline $\begin{array}{l}\text { Literacy of household head ( } 1=\text { literate, } 0= \\
\text { illiterate) }\end{array}$ & 2.651 & 1.957 & .171 & $2.218^{* *}$ & 2.033 \\
\hline $\begin{array}{l}\text { Average years of education of working-age } \\
\text { household members }\end{array}$ & $.914^{\star *}$ & $.715^{\star * *}$ & $1.252^{* *}$ & $.727^{\star \star *}$ & $.912^{* *}$ \\
\hline Real wage (daily wage in kg of cereals) & $1.120 * *$ & $1.639^{* * *}$ & .747 & $1.397^{\star \star *}$ & $1.294^{* *}$ \\
\hline Real tractor rental cost per hour & .221 & -.012 & .066 & -.039 & .007 \\
\hline $\begin{array}{l}\text { Irrigation access (sample share of farm } \\
\text { households irrigating within VDC) }\end{array}$ & .066 & .090 & .146 & .094 & .033 \\
\hline $\begin{array}{l}\text { Whether obtained credit in previous year (yes = } \\
\text { 1) }\end{array}$ & -.024 & -.013 & -.006 & $-.025^{\star *}$ & -.013 \\
\hline $\begin{array}{l}\text { Whether obtained formal credit in previous year } \\
\text { (yes = 1) }\end{array}$ & .070 & $.053^{* *}$ & $.062^{*}$ & $.070^{* * *}$ & $.061^{* *}$ \\
\hline Land area owned (lowland, ha) & $21.541^{* * *}$ & $11.426^{\star \star \star}$ & -1.234 & .496 & -.945 \\
\hline Land area owned (upland, ha) & 4.087 & $3.144^{* *}$ & -2.719 & -.868 & $-2.767^{* *}$ \\
\hline Number of owned farm plots & $3.263^{* * *}$ & $1.366^{* * *}$ & $1.402^{* * *}$ & $.506^{* *}$ & $.988^{* * *}$ \\
\hline Real household asset value-farmland & .000 & .000 & .000 & .000 & .000 \\
\hline Real household asset value_-livestock & $.006^{* * *}$ & $.004^{* * *}$ & .001 & $.002^{* * *}$ & $.002^{*}$ \\
\hline Real household asset value_farm equipment & $.004^{* * *}$ & $.002^{* \star}$ & .000 & .000 & .000 \\
\hline $\begin{array}{l}\text { Real household asset value-excluding } \\
\text { farmland, livestock, farm equipment }\end{array}$ & .000 & .000 & .000 & .000 & $.00001^{*}$ \\
\hline Ownership of draft animals ${ }^{a}$ & $.154^{\star * *}$ & $.121^{* \star *}$ & -.018 & $.044^{\star *}$ & -.018 \\
\hline Access to market center (minutes taken) & -.001 & $-.003^{\star *}$ & .000 & $-.002^{* *}$ & .000 \\
\hline$\%$ advanced caste (sample share within VDC) & $.505^{\star * *}$ & -.024 & $.804^{* * *}$ & -.043 & .239 \\
\hline $\begin{array}{l}\% \text { nonindigenous population (sample share } \\
\text { within VDC) }\end{array}$ & $.202^{*}$ & .080 & $.329^{* * *}$ & .147 & $.238^{* *}$ \\
\hline $\begin{array}{l}\text { Piped water as main source of drinking water ( } 1 \\
=\text { yes) }\end{array}$ & 2.645 & 2.748 & 2.632 & 2.589 & $3.996^{* *}$ \\
\hline Own house $(1=$ yes $)$ & 5.581 & 1.975 & -32.163 & 1.060 & .383 \\
\hline Electricity the main source of light $(1=$ yes $)$ & 4.068 & 2.144 & $8.167^{* * *}$ & $2.734^{*}$ & $7.491^{* * *}$ \\
\hline Wood the main source of cooking fuel ( $1=$ yes) & $-7.745^{\star * *}$ & $-6.325^{* * *}$ & $-11.097^{* * *}$ & $-3.948^{* * *}$ & $-8.951^{* * *}$ \\
\hline $\begin{array}{l}\text { Euclidian distance from Agriculture Research } \\
\text { Station (ARS) }\end{array}$ & 1.175 & .658 & .765 & $1.440^{* * *}$ & .891 \\
\hline $\begin{array}{l}\text { Euclidian distance from ARS in Hills \& } \\
\text { Mountains }\end{array}$ & -.991 & -1.265 & -.629 & $-2.195^{* *}$ & -1.329 \\
\hline $\begin{array}{l}\text { Euclidean distance from Indian border within } \\
\text { Terai }\end{array}$ & -15.218 & -25.240 & 2.388 & $-33.538^{*}$ & -26.222 \\
\hline Soil similarity with research station & 20.093 & 7.027 & $25.121^{* *}$ & $13.793^{*}$ & $19.047^{*}$ \\
\hline $\begin{array}{l}\text { Soil similarity with research station in Hills \& } \\
\text { Mountains }\end{array}$ & 18.930 & 15.069 & $18.653^{*}$ & 2.866 & 9.462 \\
\hline $\begin{array}{l}\text { Difference from ARS in standard deviation of } \\
\text { rainfall }\end{array}$ & $-3.665^{* * *}$ & $-1.807^{* * *}$ & $-3.467^{* * *}$ & $-1.257^{* * *}$ & $-2.691^{* * *}$ \\
\hline Sector (urban $=0$, rural $=1$ ) & $13.655^{\star * *}$ & $20.238^{* * *}$ & 8.211 & $15.911^{* * *}$ & $12.908^{* * *}$ \\
\hline Agroecological belt dummy & -10.902 & -11.752 & $-48.858^{*}$ & -1.593 & -17.821 \\
\hline District time average & Included & Included & Included & Included & Included \\
\hline Soil dummy & Included & Included & Included & Included & Included \\
\hline Year dummy & Included & Included & Included & Included & Included \\
\hline Development region dummy & Included & Included & Included & Included & Included \\
\hline Year*Agroecological belt dummy & Included & Included & Included & Included & Included \\
\hline Number of observations & 7,648 & 7,648 & 7,648 & 7,648 & 7,468 \\
\hline $\mathrm{H}_{0}$ : variables are jointly insignificant & .000 & .000 & .000 & .000 & .000 \\
\hline
\end{tabular}

Source: Authors' estimations.

Note: All monetary values including prices are in real terms measured as kilograms $(\mathrm{kg})$ of cereals. ha $=$ hectares; $\mathrm{mm}=$ millimeters. ${ }^{a}$ Draft animals are defined as bullock/cow, buffalo, horses/donkeys/mules. Asterisks indicate statistical significance: $* * * 1 \%$; * $5 \%$; $* 10 \%$. 
"Technological distance" (the similarity of a locale's soils and rainfall variability to the area where any Agriculture Research Station, or ARS, is located) seems to affect the use of chemical fertilizer. To be clear, the similarity is measured in terms of locations with any ARS in the country, not only the nearest ARS. The demand for urea is greater in an area that has a similar soil type to the area where the ARS is located. This is more strongly observed in the Hills and Mountains than in the Terai. Similarly, for both urea and DAP, demand is greater in an area that has similar rainfall variability levels to the levels in an ARS. Meanwhile, the demand for DAP in the Terai is greater in areas closer to the Indian border, where improved varieties developed in India are sometimes more accessible formally (Sah 2013) or informally (personal communication with local experts). These sets of evidence may be consistent with the hypothesis that technological distance matters in agriculture - that is, fertilizerresponsive modern varieties developed or selected in the public ARS may be more likely to have higher spillover potential to areas with similar soil types or rainfall variability, but less so to areas with different conditions. ${ }^{14}$ Farmers in developing countries are often vulnerable to rainfall risks due to their insufficient liquid assets that provide insurance (Takeshima and Yamauchi 2012; Takeshima 2015b). Not only the agroecological environment but also the relevance of agricultural research and development to each location may affect the marginal value product (MVP, which is the marginal product multiplied by the value of the product) of fertilizer nutrients. Location specificity of agricultural technologies (Evenson and Westphal 1995) may be highly relevant to the returns to nitrogen, and those returns are potentially correlated with the locations of major research programs, potentially reflecting the sparsity of agricultural research-and-development facilities in certain locations in Nepal.

Other agroecological factors seem to affect chemical fertilizer use as well. Interestingly, such use is negatively affected by higher levels of solar radiation. This somewhat contrasts with experience outside Nepal, where greater solar radiation often leads to more consistent crop responses to nutrients (Barker, Herdt, and Rose 1985). This may be driven by the particular nature in the Terai, where solar radiation may be higher in the mountainous areas even though demand for chemical fertilizer is lower, and also manure is more commonly used as a substitute for it. It is also important to note that although the coefficients for the standard deviation of rainfall are often positive, the actual effects of the standard deviation of rainfall depend on two variables (standard deviation of rainfall, and the difference from the standard deviation of rainfall in areas where an ARS is located). Therefore, the results here do not suggest that greater rainfall risk increases chemical fertilizer use. Rougher terrain negatively affects the use of chemical fertilizer.

The nutrients from fertilizing with manure, estimated based on the type of livestock held (see Table A.2 in the appendix), seem to substitute for chemical fertilizer use. This commonly applies to the Hills (excluding the central region) and the Mountains, and to some extent to the Terai. This is somewhat contradictory to findings in other countries, such as Niger, where the two have been found complementary (Abdoulaye and Sanders 2005).

Use of DAP is positively affected by the real wage, indicating that labor and DAP are substitutes in Nepal. However, the magnitude of the effect is small. Similarly, while having obtained formal credit in previous years is positively associated with chemical fertilizer use, the effect is small, on the order of less than 1 kilogram.

Fertilizer use per cultivated area is not affected by size of land owned. Number of plots, however, is generally positively associated with fertilizer use.

Having better educated working-age household members is commonly positively associated with chemical fertilizer use. Household size, having a male household head, and the literacy of household heads are also sometimes positively associated with fertilizer use.

Having greater household assets in the form of livestock or farm equipment is associated with greater use of chemical fertilizer as well, although no such relationship is found for other household

\footnotetext{
${ }^{14}$ Strictly speaking, more detailed information on location-specific soil types may be available from the local soil testing labs. However, we do not include such information here as it is not readily available.
} 
assets. Among livestock, specifically owning draft animals is also positively associated with use of chemical fertilizer, although the magnitude of the effect is small.

Having access to piped water and having electricity as the main source of lighting are each positively associated with chemical fertilizer use, while using wood as the main source of fuel is negatively associated with it. This is consistent with the hypothesis that these factors affect the availability of family labor, which is often the major source of labor for farming and may be complementary to chemical fertilizer use. Note that this appears to contrast with the positive effects of real wages mentioned earlier, but this may reflect an imperfect labor market where family labor and hired labor are not perfect substitutes.

\section{Price Responsiveness of Chemical Fertilizer Use}

Using the results in Table 5.1, the average partial effects (APE) of price on fertilizer use is calculated as

$$
A P E=E\left[\widehat{\gamma_{p}} \Phi\left(\frac{x \hat{\beta}}{\hat{\sigma}}\right)\right],
$$

where $\widehat{\gamma_{p}}$ represents the estimated coefficients (including the coefficients for price interaction terms times the interacted variables), $\hat{\beta}$ represents the estimated coefficients for all variables and include $\widehat{\gamma_{p}}, \hat{\sigma}$ is an estimated parameter, and $\Phi$ is the standard normal distribution function.

Table 5.2 summarizes the estimated sample average price responses of urea and DAP in each agroecological belt (Hills and Mountains are combined) in 1995, 2003, and 2010. The figures are the changes in kilograms of fertilizer used per farm household in response to a one-unit increase in the real price of the corresponding chemical fertilizer or the average prices of these fertilizers, where the unit is the value of 1/100 kilogram of cereals. For example, -.256 means that in the Terai in 1995, a one-unit increase (decrease) in urea price reduced (increased) the farm household's purchase of urea by 0.256 kilogram on average, ceteris paribus.

Table 5.2 Average partial price response of fertilizer demand (change in kilograms of fertilizer demand per farm household in response to a one-unit increase in real price)

\begin{tabular}{llccc}
\hline Fertilizer & Agroecological belt & $\mathbf{1 9 9 5}$ & $\mathbf{2 0 0 3}$ & $\mathbf{2 0 1 0}$ \\
\hline Urea & Terai & $-.256^{*}(.151)$ & $-.235^{\star * *}(.073)$ & $-.511^{* \star *}(.082)$ \\
& Hills (excluding central zone) & $-.013(.072)$ & $-.025(.041)$ & $-.086^{* *}(.037)$ \\
& and Mountains & & & \\
\hline DAP & Terai & $-.206^{* * *}(.069)$ & $-.143(.090)$ & $-.529^{*}(.304)$ \\
& Hills (excluding central zone) & $-.037(.026)$ & $-.020(.028)$ & $-.108^{* *}(.042)$ \\
& and Mountains & & & \\
\hline Nutrients per & Terai & $-.055(.105)$ & $-.046(.057)$ & $-.201^{* *}(.097)$ \\
$\begin{array}{l}\text { cultivated area } \\
(\mathrm{kg} / \mathrm{ha})^{\mathrm{a}}\end{array}$ & Hills (excluding central zone) & $-.000(.094)$ & $-.003(.036)$ & $-.051(.034)$ \\
\hline
\end{tabular}

Source: Authors' calculations.

Note: One unit is the value of 1/100 kilogram of cereals, as we refer to the real price of chemical fertilizer, deflated by the cereal price. Figures are assessed at the mean values of samples. Figures in parentheses are standard errors, estimated through bootstrapping taking into account the sample weights and stratification. ${ }^{\text {a }}$ Figures are with respect to the average price of urea and DAP.

The sample average price responsiveness has generally increased since 2003 for both urea and DAP in all agroecological belts. The average price responsiveness has been generally greater in the Terai, and seems to have further diverged over time. In 1995 and 2003, average price responsiveness for Urea was statistically significant only in the Terai. In 2010, it was statistically significant in both the Terai and the Hills and Mountains, but the significance was greater in the Terai. Similar evidence also 
exists for DAP or nutrients per cultivated area, although it is weaker. ${ }^{15}$ The results indicate that reducing fertilizer price through subsidies may induce greater use in the Terai than in the Hills and Mountains.

Note that this also applies to reducing fertilizer price through transportation subsidies, because prices in our analysis are those that prevail in the local market, which also reflect the cost of transporting fertilizer to those locations.

Under the standard economic conditions, the price response of chemical fertilizer is greater if its marginal value product does not diminish rapidly as the intensity of its use increases. In the next section, we provide some evidence for this.

\section{Gross Returns to Chemical Fertilizer Use}

Figures 5.1 through 5.4 illustrate the estimated effects of quantities (kilograms) of nutrients from chemical fertilizer used by the household on the natural log of household income (measured in kilograms of cereals), for each subgroup of farm households classified as above. Importantly, Figures 5.1 through 5.4 are based on the assumption of free fertilizer price. We used such a specification so that the comparisons in returns to fertilizer use between the Terai and the Hills excluding the central region are not affected by the observed lower fertilizer prices in the Terai relative to the Hills, as shown in Tables 3.6 and 3.7.

\section{Figure 5.1 Small-size, low-asset owner}
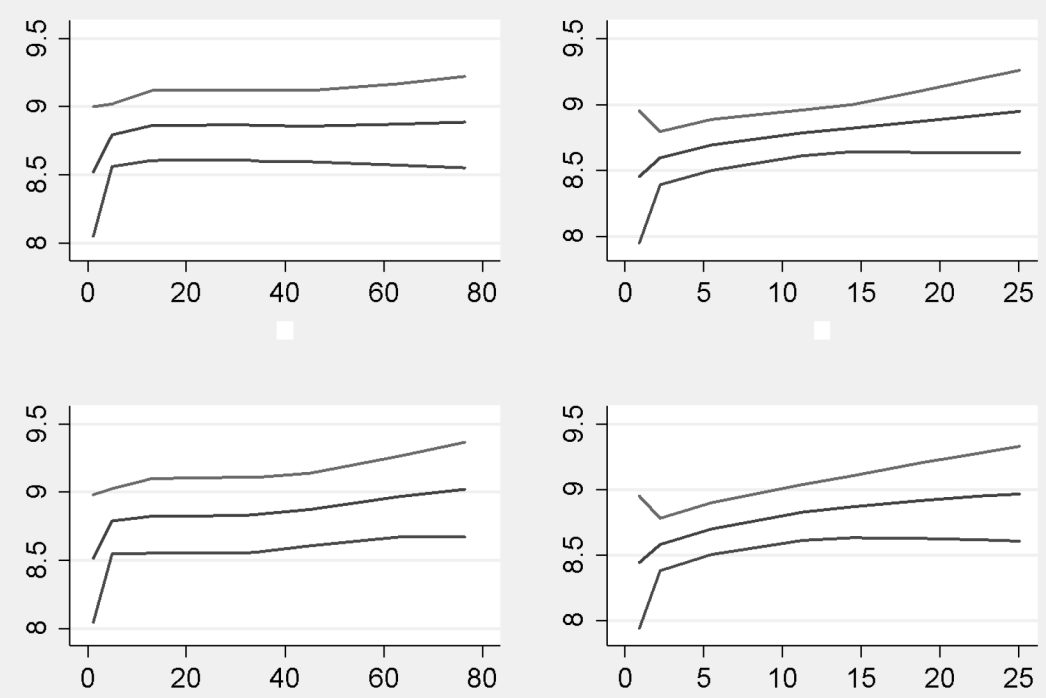

Source: Authors.

Note: $\quad$ Left $=$ Terai; right $=$ Hills excluding central region; top $=$ short specification; bottom $=$ full specification. The lines show the mean estimates as well as the $90 \%$ confidence interval based on 100 bootstrap processes. The vertical axis measures the natural log of annual household income measured in terms of kilograms of cereals valued at local prices. The horizontal axis measures chemical fertilizer nutrients used (kilograms per household per year).

${ }^{15}$ Although the price variables are generally insignificant for chemical fertilizer nutrients per kilogram in Table 5.1 (the last column), the average partial effects in 2010 are statistically significant in Table 5.2 (-.201), because the latter are calculated as combinations of coefficients for price variables as well as other variables, as shown in the formula above. 
Figure 5.2 Small-size, high-asset owner
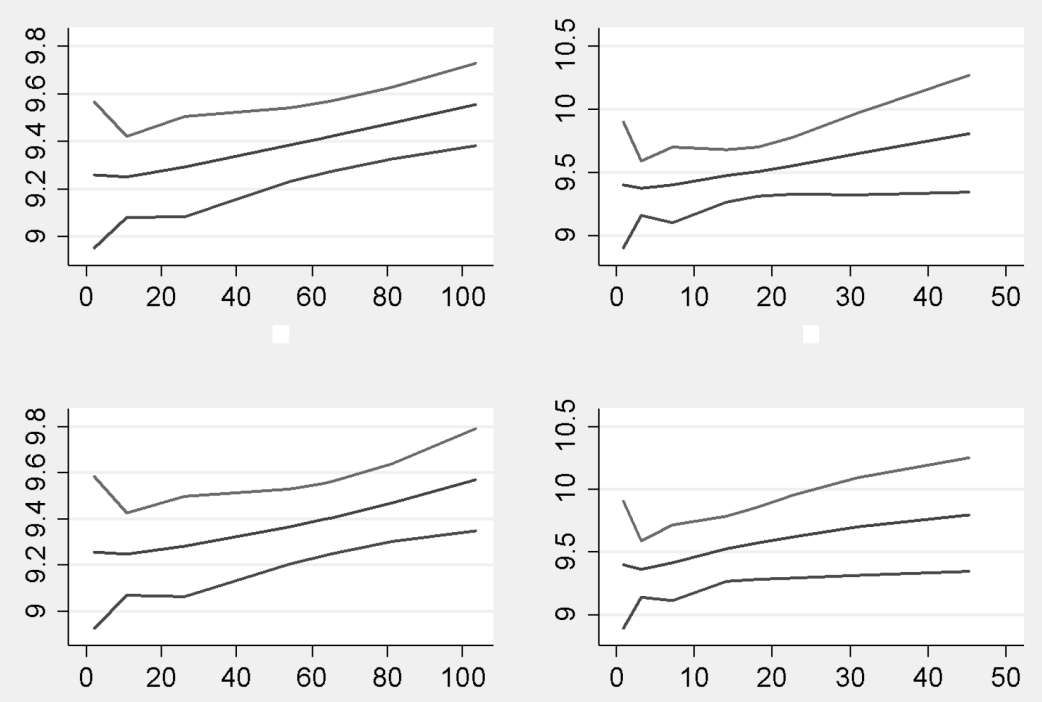

Source: Authors.

Note: $\quad$ Left $=$ Terai; right $=$ Hills excluding central region; top $=$ short specification; bottom $=$ full specification . The lines show the mean estimates as well as the $90 \%$ confidence interval based on 100 bootstrap processes. The vertical axis measures the natural log of annual household income measured in terms of kilograms of cereals valued at local prices. The horizontal axis measures chemical fertilizer nutrients used (kilograms per household per year).

Key patterns are summarized as follows: Small-size, low-asset owners do not exhibit statistically significant returns from the increased use of chemical fertilizer (Figure 5.1). For small-size, high-asset owners, returns from chemical fertilizer use appear to increase up to a certain level in the Terai, while the statistical significance for the Hills is low (Figure 5.2). For medium-scale, low-asset farmers, returns to chemical fertilizer in the Terai seem to maximize around 100 to 150 kilograms of nutrients with statistical significance, while patterns are less clear for the Hills (Figure 5.3). For medium-sale, high-asset farmers, patterns are less precise than for low-asset farmers, but again the returns in the Terai seem to exhibit clearer signs that the marginal returns are statistically significantly positive up to a certain level of chemical fertilizer (Figure 5.4).

Note, we are talking about the nutrients per household given their existing size distributions. Farmers may be using chemical fertilizer in much smaller quantities than the optimal quantities indicated in Figures 5.1 through 5.4. This is primarily because most farmers face constraints in certain inputs like land.

Altogether, the GPSM results suggest that income effects of chemical fertilizer use for the typical household in each subgroup continue to rise to a much higher level in the Terai than they do in the Hills, often on the order of three times or more, particularly among larger-size households. It is important to note that these differences are only partly driven by the differences in the typical size of total land cultivated. As was shown in Table 4.3, the typical cultivated areas in each subgroup do not differ by more than 50 percent between the Terai and the Hills. The GPSM results therefore suggest that income returns from intensive chemical fertilizer use per cultivated area are inherently higher than those in the Hills. 
Figure 5.3 Medium-to-large-size, low-asset owner
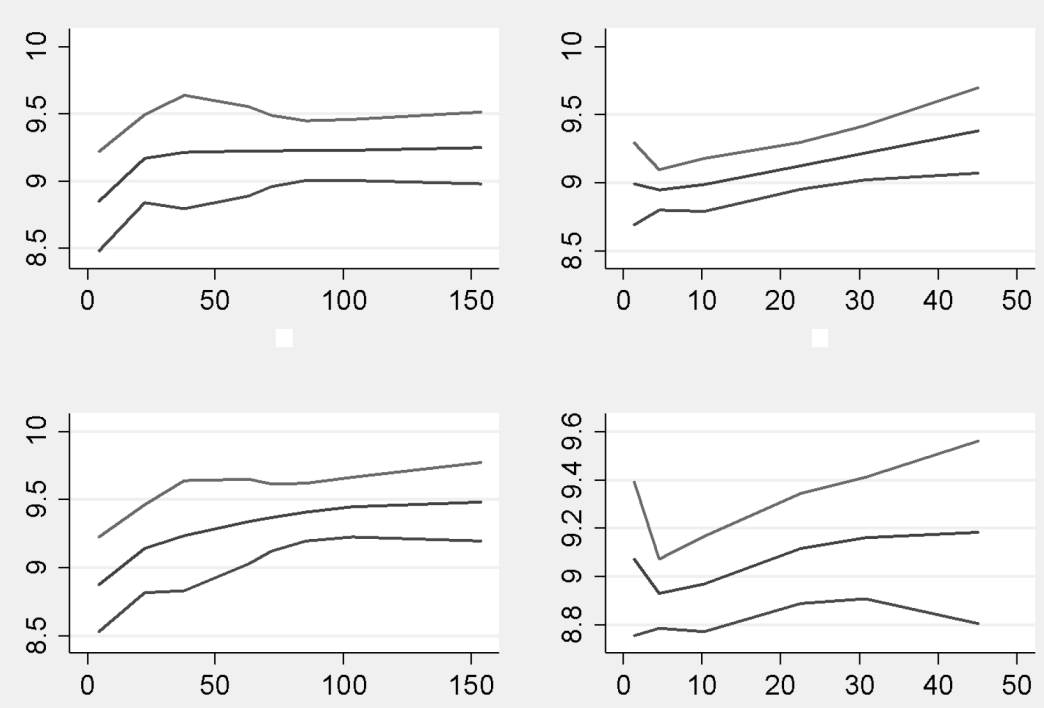

Source: Authors.

Note: $\quad$ Left $=$ Terai; right $=$ Hills excluding central region; top $=$ short specification; bottom $=$ full specification. The lines show the mean estimates as well as the $90 \%$ confidence interval based on 100 bootstrap processes. The vertical axis measures the natural log of annual household income measured in terms of kilograms of cereals valued at local prices. The horizontal axis measures chemical fertilizer nutrients used (kilograms per household per year).

Figure 5.4 Medium-to-large-size, high-asset owner
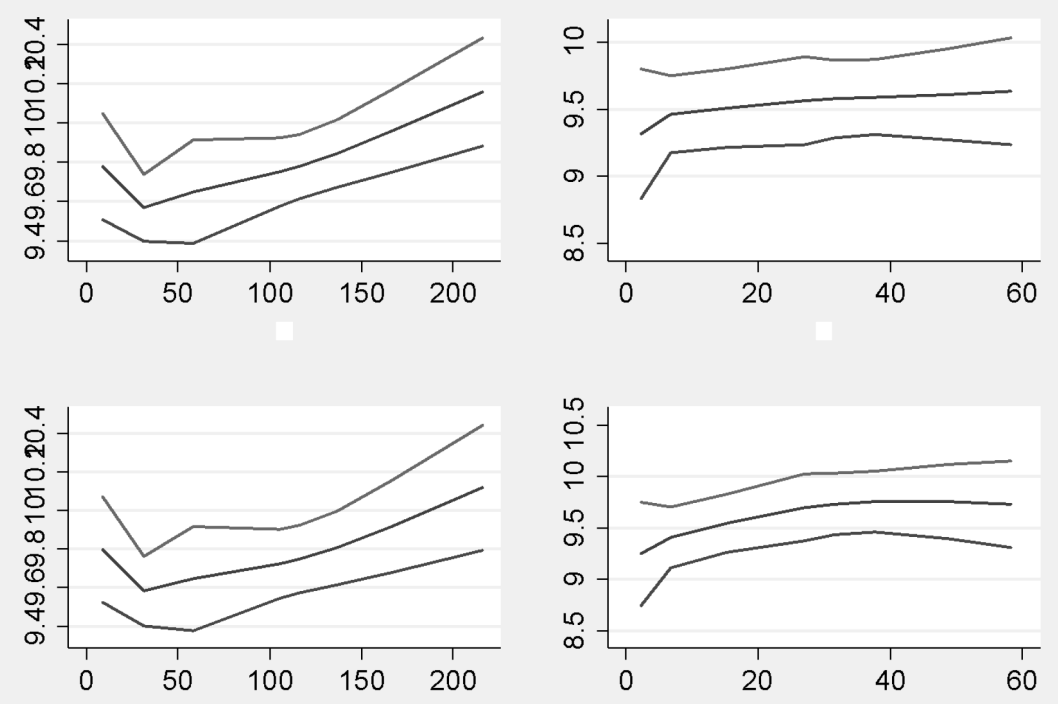

Source: Authors.

Note: $\quad$ Left $=$ Terai; right $=$ Hills excluding central region; top $=$ short specification; bottom $=$ full specification. The lines show the mean estimates as well as the $90 \%$ confidence interval based on 100 bootstrap processes. The vertical axis measures the natural log of annual household income measured in terms of kilograms of cereals valued at local prices. The horizontal axis measures chemical fertilizer nutrients used (kilograms per household per year). 
Even though the returns from the intensive use of chemical fertilizer are low, using small quantities may have significant income effects versus not using chemical fertilizer at all. However, that is not the case. Table 5.3 shows the estimated effects of using small quantities of chemical fertilizer (with varying thresholds of 10 kilograms and 20 kilograms) on real per capita household income. Since only the marginal chemical fertilizer users are the focus here, their characteristics are relatively homogenous and many such marginal users have similar characteristics to nonusers of chemical fertilizer, leading to sufficient balancing properties of the PSM (Table 5.5). As Table 5.3 shows, under various specifications, the income effects of marginal adoption of chemical fertilizer are statistically insignificant, indicating that marginal adoption is not associated with positive returns. Combined with the findings from Figures 5.1 through 5.4, returns from the intensive use of chemical fertilizer are higher in the Terai than in the Hills outside the central region, while returns from marginal use are insignificant in both regions.

Overall, patterns are consistent with Figure 3.1. There appears to be a significant difference in returns to chemical fertilizer between the Terai and the Hills outside the central zone, and the difference is greater among medium-to-large-scale farmers. In the Terai, chemical fertilizer can be applied fairly intensively per unit of area across medium-to-large-scale farms, and still generate sufficient profits. This is also consistent with the finding in Takeshima, Adhikari, and Poudel (2016) that the pattern of input use intensification in the Terai is largely homothetic and the intensive use of chemical fertilizer is often associated with greater use of mechanization and land. In the Hills outside the central zone, on the other hand, raising the intensity of chemical fertilizer per unit of area among medium-to-large-scale farms will face rapidly declining returns. Investigating the causes of such a difference is beyond the scope of this paper, although the growth in technologies that can generate greater scale effects, such as tractors (Takeshima 2015c), in the Terai may be one cause. At least, we can see that such differences in returns are partly driving the greater price responsiveness of chemical fertilizer demand in the Terai compared with that in the Hills.

Table 5.3 Income effects of marginal adoption of chemical fertilizer

\begin{tabular}{|c|c|c|c|c|c|c|}
\hline \multirow[b]{2}{*}{$\begin{array}{l}\text { Thresholds } \\
\text { (kg of } \\
\text { chemical } \\
\text { fertilizer } \\
\text { nutrients) }\end{array}$} & \multicolumn{3}{|l|}{ Terai } & \multicolumn{3}{|c|}{ Hills excluding central zone } \\
\hline & $\begin{array}{l}\text { Nearest } \\
\text { neighbor } \\
\text { with } \\
\text { calipera,b }\end{array}$ & $\begin{array}{l}\text { Nearest } \\
\text { neighbor } \\
\text { without } \\
\text { caliper }\end{array}$ & Mahalanobis & $\begin{array}{l}\text { Nearest } \\
\text { neighbor } \\
\text { with caliper }\end{array}$ & $\begin{array}{l}\text { Nearest } \\
\text { neighbor } \\
\text { without } \\
\text { caliper }\end{array}$ & $\begin{array}{l}\text { Mahalanob } \\
\text { is }\end{array}$ \\
\hline 10 & $-.012(.093)$ & $.005(.089)$ & $.039(.074)$ & $-.011(.057)$ & $-.038(.061)$ & $\begin{array}{l}-.029 \\
(.056)\end{array}$ \\
\hline 20 & $\begin{array}{c}.006 \\
(.087)\end{array}$ & $-.028(.070)$ & $-.005(.088)$ & $-.028(.053)$ & $-.035(.057)$ & $.002(.051)$ \\
\hline
\end{tabular}

Source: Authors' estimations.

Note: $\mathrm{kg}=$ kilograms. ${ }^{\text {a }}$ The maximum number of control group observation matched with each treatment group observation is 4 . ${ }^{b}$ For caliper, we use 0.01 , meaning that for each treatment group observation, only the control group observations whose propensity scores are not more than 0.01 away from that of treatment group observation, are included for comparison.

Balancing tests in GPSM are conducted by comparing GPS-adjusted means of covariates across subgroups that are defined based on treatment levels (hectares). Following the standard approach (Hirano and Imbens 2004; Kluve et al. 2007), we conduct this test in the following way; we split the sample into three groups $G_{j}(j=1,2,3)$ by the tertiles of treatment level, divide each group into five blocks $G_{j k}(k=1,2,3,4,5)$ based on the quintiles of the GPS $R\left(T_{j}^{m}, X\right)$ evaluated at the median treatment level within the tertile $j\left(T_{j}^{m}\right)$, calculate the $t$-statistics for the equality of means of covariates $X$ s between blocks $G_{j k}$ and $G_{\zeta k}(\zeta \neq j)$. For most samples, approximately 5 percent of the absolute values of $t$-statistics exceed 1.96, which is what we expect under the null hypothesis that means of $X \mathrm{~s}$ are jointly equal across groups (the right-most column of Table 5.4). Only for one group in the Terai 
(small-scale, high-asset), the frequency is slightly higher, around 10 percent, indicating that the balancing properties may be questionable for this group. However, the medium-to-large-size farmers in the Terai, from which we draw several important conclusions, seem to have satisfactory balancing properties. Overall, the main messages on the differences in returns to chemical fertilizer use assessed through GPSM seem to be valid.

Table 5.4 Balancing properties under generalized propensity score matching

\begin{tabular}{lccc}
\hline Zone & $\begin{array}{l}\text { Own land size } \\
\text { (hectares) }\end{array}$ & $\begin{array}{l}\text { Real household assets } \\
\text { (kilograms of cereals } \\
\text { equivalent) }\end{array}$ & $\begin{array}{l}\text { \% of covariates whose means } \\
\text { are statistically significantly } \\
\text { different from other groups }\end{array}$ \\
\hline Terai & $<0.5$ & $<25,000$ & 3.1 \\
& $0.5 \sim 5.0$ & $\geq 25,000$ & 8.7 \\
\cline { 2 - 4 } & $0.5 \sim 1.5$ & $<75,000$ & 5.3 \\
& $<0.5$ & $\geq 75,000$ & 5.7 \\
\hline Hills outside the & & $<30,000$ & 6.7 \\
central zone & $>0.5$ & $\geq 30,000$ & 3.9 \\
\cline { 2 - 4 } & & $<50,000$ & 5.3 \\
\hline
\end{tabular}

Source: Authors.

Note: $\wedge$ Statistical significance at $5 \%$ based on the $t$-test.

Similarly, the balancing properties of PSM are presented in Table 5.5. Rubin (2001) proposes two statistics-Rubin's B and Rubin's R. A Rubin's B value of less than 0.4 indicates that the differences in covariates between treatment and control groups are "arguably minor enough" (Rubin 2001,181). Similarly, Rubin's R should be between 0.5 and 2 for the balancing properties to be satisfied (Rubin 2001). In addition, similar to the case for GPSM above, not more than 5 percent of covariates should have means statistically significantly different at 5 percent significance across treatment and control groups. Table 5.5 shows that these conditions hold for both the Terai and the Hills (excluding the central region) samples.

Table 5.5 Balancing properties of propensity score matching for marginal users of fertilizer (using chemical fertilizer nutrients of not more than 20 kilograms per year)

\begin{tabular}{lcc}
\hline Criteria & Terai & $\begin{array}{l}\text { Hills excluding central } \\
\text { region }\end{array}$ \\
\hline Rubin's B & 0.349 & 0.333 \\
\hline Rubin's R & 0.90 & 0.97 \\
\hline $\begin{array}{l}\text { \% of covariates with statistically significantly } \\
\text { different means between fertilizer users and } \\
\text { nonusers }\end{array}$ & 0 & 3 \\
\hline
\end{tabular}

Source: Authors. 


\section{SUMMARY AND CONCLUSION}

Some inferences can be drawn from the preceding analysis. First, in mountainous regions like Nepal (particularly in the Hills and the Mountains zones), the potential and the technology for increased use of manure have major implications for the demand for inorganic fertilizer, unlike in other countries consisting of relatively more flat areas. Technological improvements such as in Europe can potentially increase the industrialized supply of manure and compost in Nepal. Analysis of the adoption of inorganic fertilizer in Nepal must take into account such potential improvements and farmers' demand for these technologies, although more thorough analyses are needed including the careful measurement of the quantities of organic fertilizer used in Nepal.

This study's empirical analysis provides a richer story regarding the determinants of chemical fertilizer use and its regional variations. The price responsiveness of chemical fertilizer use is lower in the Hills and Mountains than the Terai. This is partly because of low returns to chemical fertilizer use in the Hills (outside the central region) relative to returns in the Terai, particularly among medium-tolarge-size farmers that own more than 0.5 hectare of farmland and use the majority of chemical fertilizer in each region.

One of the important determinants of chemical fertilizer use is geographical characteristics, particularly in relation to Agriculture Research Stations. Distance from an ARS affects total-factor productivity or fertilizer use efficiency (we cannot separate them in this study) and thus the demand for fertilizer. Distances to other institutions may matter as well. The similarity of local agroecological conditions to those that prevail in an area where an ARS is located generally raises chemical fertilizer use. One reason might be ARS outreach programs in areas of similar agroecological conditions and dissemination of technological knowledge to farmers. In the Terai, distance from the Indian border reduces chemical fertilizer use (even after controlling for fertilizer price, which is itself affected by proximity to the Indian border).

Lastly, evidence on imperfections in the chemical fertilizer market is generally weak. Shares in that market occupied by the government, NGOs, and cooperatives relative to the private market do not vary substantially and are relatively small (though statistically significantly different) across regions. A substantial portion of the growth in fertilizer demand has been met by private markets, despite the possibility that chemical fertilizer from the private markets is often inferior and adulterated, relative to the chemical fertilizer supplied by the government, NGOs, and cooperatives. Agricultural finance seems unlikely to be a major constraint against fertilizer use, as only a fraction of farmers used credit/loans to obtain fertilizer. The PSM results suggest that the marginal adoption of chemical fertilizer does not lead to a significant income increase, and that is consistent with the hypothesis that the accessibility of chemical fertilizer is not constraining farmers.

Overall, our results suggest that policies aimed at increasing the use of chemical fertilizer in Nepal, particularly in the Hills and the Mountains, may need to focus on how to raise the returns from chemical fertilizer instead of on reducing the price of chemical fertilizer through subsidies. Enhanced investment into agricultural research and development on production technologies (for example, varieties) may be a key option. Studies around the world, both in Asia and other developing regions like Africa, show that fertilizer subsidies may not significantly induce fertilizer use or lead to other intended objectives like containment of food price increases (Rashid et al. 2013; Liverpool-Tasie and Takeshima 2013; Takeshima and Liverpool-Tasie 2015).

Further research is needed to understand why returns to chemical fertilizer differ between medium-to-large-size farmers in the Terai and those in the Hills. This may be associated with the growing mechanization in the Terai relative to the Hills (Takeshima 2015c), but more rigorous assessment is needed to establish the causality. 
In addition, further research is needed to better understand the interactions between chemical and organic fertilizer and the returns to fertilizer use taking into account longer-term environmental sustainability. Specifically, a policy option that would package inorganic and organic fertilizer in a subsidy warrants study to see its effect on increasing fertilizer use without compromising soil quality. 


\section{APPENDIX: CALCULATION OF NUTRIENT QUANTITIES (INORGANIC AND ORGANIC)-NITROGEN, PHOSPHOROUS, AND POTASSIUM}

The nitrogen component of inorganic fertilizer was estimated using the following formula: urea $=45$ percent of fertilizer weight, complex $=17.5$ percent, $\mathrm{DAP}=18$ percent, and other fertilizer $=20$ percent. The nitrogen component of manure per head of livestock was estimated using the following formula, assessed by the author from FAOSTAT: bullock/cow $=4.4$ kilograms per head, buffalo $=9$ kilograms, goat $=0.75$ kilograms, sheep $=2$ kilograms, pig $=4$ kilograms, and poultry $=0.25$ kilogram . Specifically, it was calculated by dividing the reported manure nitrogen sourced from different types of livestock by the number of each type of livestock in the country.

Table A.1 Estimated nutrient composition of inorganic fertilizer used in the study

\begin{tabular}{lccc}
\hline Nutrient & Nitrogen & Phosphate & Potassium \\
\hline Urea & 45 & 0 & 0 \\
NPK Complex & 16.7 & 23.5 & 15 \\
DAP & 18 & 46 & 0 \\
Other & 26.6 & 23.2 & 5 \\
\hline
\end{tabular}

Source: Authors, based on various sources including FAO (2005).

Note: The composition of NPK complex is calculated as the average of all types of NPK fertilizer reportedly produced in India (FAO 2005). The composition of "Other" fertilizer is estimated as the simple average composition of the three major types of fertilizer.

Table A.2 Estimated manure nutrients sourced from different types of livestock

\begin{tabular}{lcccccc}
\hline & \multicolumn{2}{l}{$\begin{array}{l}\text { \% of nutrients in manure (fresh weight) } \\
\text { (Dalzell 1987) }\end{array}$} & \multicolumn{3}{c}{$\begin{array}{l}\text { Effective nutrients applied to soil sourced from } \\
\text { manure in Nepal per head of livestock (kg) }\end{array}$} \\
\cline { 2 - 7 } Source & Nitrogen & Phosphate & Potassium & Nitrogen & Phosphate & Potassium \\
\hline Bullock/cow & 0.6 & 0.13 & 0.66 & 4.4 & 0.95 & 4.84 \\
Buffalo & 0.6 & 0.13 & 0.66 & 9.0 & 1.95 & 9.90 \\
Goat & 0.6 & 0.13 & 0.99 & 0.75 & 0.1625 & 1.2375 \\
Sheep & 0.6 & 0.13 & 0.99 & 2.0 & 0.43 & 3.3 \\
Pig & 0.5 & 0.18 & 0.42 & 4.0 & 1.44 & 3.36 \\
Poultry & 1.46 & 0.51 & 0.51 & 0.25 & 0.087 & 0.087 \\
\hline
\end{tabular}

Source: Authors' calculations based on FAOSTAT, and figures for China in Dalzell (1987, Table 10).

Note: ${ }^{a}$ Manure nitrogen applied to soil is calculated by dividing the total manure nitrogen applied to soil by the number of livestock of different types in the most recent years reported in FAOSTAT. Corresponding figures for phosphate and potassium are extrapolated using that nitrogen figure and the proportions of nitrogen, phosphate, and potassium reported in Dalzell (1987) for China. 


\section{REFERENCES}

Abdoulaye, T., and J. H. Sanders. 2005. "Stages and Determinants of Fertilizer Use in Semiarid African Agriculture: The Niger Experience.” Agricultural Economics 32 (2): 167-179.

ADB (Asian Development Bank). 2013. Draft Final Report. Technical Assistance for the Preparation of the Agricultural Development Strategy. 7762-NEP. Washington, DC.

APROSC (Agricultural Projects Services Centre). 1995. Nepal Agriculture Perspective Plan. Kathmandu, Nepal: Agricultural Projects Services Centre, Washington DC: John Mellor Associates, Inc.

Aryal, J. P., and S. T. Holden. 2013. "Land Reforms, Caste Discrimination, and Land Market Performance in Nepal." In Land Tenure Reform in Asia and Africa: Assessing Impacts on Poverty and Natural Resource Management, edited by S. Holden, 29-53. Basingstoke, UK. Palgrave Macmillan.

Barker, R., R. W. Herdt, and B. Rose. 1985. The Rice Economy of Asia. Washington, DC: Resources for the Future.

Bia, M., and A. Mattei. 2008. "A Stata Package for the Estimation of the Dose-Response Function through Adjustment for the Generalized Propensity Score." The Stata Journal 8 (3): 354-373.

Binswanger, H. and G. Donovan. 1987. Agricultural Mechanization: Issues and Options. Washington, DC: World Bank.

Dalzell, H. W. 1987. Soil Management: Compost Production and Use in Tropical and Subtropical Environments. FAO Soils Bulletin 56. Rome: Food and Agriculture Organization.

Deaton, A. 1997. The Analysis of Household Surveys: A Microeconomic Approach to Development Policy. Baltimore: Johns Hopkins University Press.

Evenson, R., and L. E. Westphal. 1995. "Technological Change and Technology Strategy." In Handbook of Development Economics, edited by J. Behrman and T. N. Srinivasan, 2209-2299. Amsterdam: Elsevier.

FAO (Food and Agriculture Organization of the United Nations). 2005. Fertilizer Use by Crop in India. Rome. www.fao.org/docrep/009/a0257e/A0257E00.htm\#TOC.

2015. FAOSTAT database. Rome.

FAO / IIASA (International Institute for Applied Systems Analysis) / ISRIC (International Soil Reference and Information Centre) / ISSCAS (Institute of Soil Science-Chinese Academy of Sciences) / JRC (Joint Research Centre of the European Commission). 2012. Harmonized World Soil Database, version 1.2. Rome: FAO; Laxenburg, Austria: IIASA.http://webarchive.iiasa.ac.at/Research/LUC/External-Worldsoil-database/HTML/.

Gao, L., J. Huang, and S. Rozelle. 2012. "Rental Markets for Cultivated Land and Agricultural Investments in China." Agricultural Economics 43 (4): 391-403.

Gellner, D. N. 2007. "Caste, Ethnicity, and Inequality in Nepal.” Economic and Political Weekly 42 (20): 18231828.

Hirano, K., and G. W. Imbens. 2004. "The Propensity Score with Continuous Treatments." In Applied Bayesian Modeling and Causal Inference from Incomplete-Data Perspectives, edited by A. Gelman and X. L. Meng, 73-83. New York. Wiley.

Jacoby, H. G. 1993. "Shadow Wages and Peasant Family Labour Supply: An Econometric Application to the Peruvian Sierra." Review of Economic Studies 60 (4): 903-921.

Kajisa, K., and N. V. Palanichamy. 2011. "Potential and Limitation of an Organic Fertilizer-Based Development Strategy: Evidence from Tamil Nadu, India, from 1993 to 2003." Agricultural Economics 42 (6): 715725 .

Kluve, J., H. Schneider, A. Uhlendorff and Z. Zhao. 2007. Evaluating Continuous Training Programs Using the Generalized Propensity Score. IZA Discussion Paper 3255. Bonn, Germany: Institute for the Study of Labor. 
Liverpool-Tasie, S., and H. Takeshima. 2013. "Input Promotion within a Complex Subsector: Fertilizer in Nigeria." Agricultural Economics 44 (6): 581-594.

Nepal, CBS (Central Bureau of Statistics). 1996. Nepal Living Standards Survey Report 1996: Main Findings. Vol. 1. Computer disk. Washington, DC.

- 2001. Population and Housing Census 2001. Computer disk. Washington, DC.

2004. Nepal Living Standards Survey II (2003/04): Survey Design and Implementation. Computer disk. Washington, DC.

2011a. Nepal Living Standards Survey 2011/11: Statistical Report. Vol. 1. Computer disk. Washington, DC.

—. 2011b. Population and Housing Census 2011. Computer disk. Washington, DC.

Nunn, N., and D. Puga. 2012. "Ruggedness: The Blessing of Bad Geography in Africa." Review of Economics and Statistics 94 (1): 20-36.

Pandey, S. 2013. "Role of Fertilizer in Transforming Agricultural Economy in Nepal.” Unpublished report prepared for RESAKSS-ASIA, Washington, DC.

Pilbeam, C. J., B. P. Tripathi, D. P. Sherchan, P. J. Gregory, and J. Gaunt. 2000. "Nitrogen Balances for Households in the Mid-Hills of Nepal. Agriculture, Ecosystems, and Environment 79 (1): 61-72.

Quizón, J., and H. Binswanger. 1986. "Modeling the Impact of Agricultural Growth and Government Policy on Income Distribution in India." World Bank Economic Review 1 (1): 103-148.

Ramankutty, N., A. T. Evan, C. Monfreda, and J. A. Foley. 2008. "Farming the Planet: 1. Geographic Distribution of Global Agricultural Lands in the Year 2000." Global Biogeochemical Cycles 22 (1): 1-19.

Rashid, S., P. A. Dorosh, M. Malek, and S. Lenma. 2013. "Modern Input Promotion in Sub-Saharan Africa: Insights from Asian Green Revolution. Agricultural Economics 44 (6): 705-721.

Riley, S. J., S. D. DeGloria, and R. Elliot. 1999. "A Terrain Ruggedness Index That Quantifies Topographic Heterogeneity." Intermountain Journal of Sciences 5 (1-4): 23-27.

Robinson, P. 1982. "On the Asymptotic Properties of Estimators of Models Containing Limited Dependent Variables." Econometrica 50: 27-41.

Rubin, D. B. 2001. "Using propensity scores to help design observational studies: application to the tobacco litigation." Health Services and Outcomes Research Methodology 2 (3-4), 169-188.

Sah, R. 2013. Role of Seeds in Transforming Agriculture in Nepal. Report submitted for ReSAKSS Asia facilitated by International Food Policy Research Institute. Computer disk. Washington, DC.

Takeshima, H. 2015a. "Identifying the Effects of Market Imperfections for a Scale Biased Agricultural Technology: Tractors in Nigeria." Paper presented at the triennial conference of the International Association of Agricultural Economists, Milan, Italy, August 8-14.

2015b. “Onset Risks and Draft Animal Investment in Nigeria." Journal of International Agricultural Trade and Development 9 (2): 137-163.

-2015c. Drivers of Growth in Agricultural Returns to Scale: The Hiring In of Tractor Services in the Terai of Nepal. IFPRI Discussion Paper 01476. Washington, DC: International Food Policy Research Institute.

Takeshima, H., R. P. Adhikari, M. N. Poudel, and A. Kumar 2016. Farm Household Typologies and Mechanization Patterns in Nepal Terai: Descriptive Analysis of Nepal Living Standard Surveys. IFPRI Discussion Paper 01488. Washington, DC: International Food Policy Research Institute.

Takeshima, H., and L. S. Liverpool-Tasie. 2015. "Fertilizer Subsidy, Political Influence, and Local Food Prices in Sub-Saharan Africa: Evidence from Nigeria." Food Policy 54: 11-24.

Takeshima, H., and L. Nagarajan. 2012. "Minor Millets in Tamil Nadu, India: Local Market Participation, OnFarm Diversity and Farmer Welfare." Environment and Development Economics 17 (5): 603-632. 
Takeshima, H., and E. Nkonya. 2014. "Government Fertilizer Subsidy and Commercial Sector Fertilizer Demand: Evidence from the Federal Market Stabilization Program (FMSP) in Nigeria." Food Policy 47: 1-12.

Takeshima, H., and F. Yamauchi. 2012. "Risks and Farmers' Investment in Productive Assets in Nigeria." Agricultural Economics 43 (2): 143-153.

Thorne, P. J., and J. C. Tanner. 2002. "Livestock and Nutrient Cycling in Crop-Animal Systems in Asia." Agricultural Systems 71 (1): 111-126.

USGS (U.S. Geological Survey). 1996. GTOPO30. Sioux Falls, SD, US: USGS Center for Earth Resources Observation and Science. 




\section{RECENT IFPRI DISCUSSION PAPERS}

\section{For earlier discussion papers, please go to www.ifpri.org/pubs/pubs.htm\#dp. All discussion papers can be downloaded free of charge.}

1505. Volatile volatility: Conceptual and measurement issues related to price trends and volatility. Eugenio Díaz-Bonilla, 2016.

1504. Changes in Ghanaian farming systems: Stagnation or a quiet transformation? Nazaire Houssou, Michael Johnson, Shashidhara Kolavalli, and Collins Asante-Addo, 2016.

1503. Returns to agricultural public spending in Ghana: Cocoa versus Noncocoa subsector. Samuel Benin, 2016.

1501. Challenges in implementing a small-scale farmers' capacity-building program: The case of the food production, processing, and marketing project in the Democratic Republic of Congo. Catherine Ragasa, Ephraim Nkonya, John Ulimwengu, and Josée Randriamamonjy, 2016.

1500. Leveling the field for biofuels: Comparing the economic and environmental impacts of biofuel and other export crops in Malawi. Franziska Schuenemann, James Thurlow, and Manfred Zeller, 2016.

1499. Farm transition and indigenous growth: The rise to medium- and large-scale farming in Ghana. Nazaire Houssou, Antony Chapoto, and Collins Asante-Addo, 2016.

1498. The impact of agricultural extension services in the context of a heavily subsidized input system: The case of Malawi. Catherine Ragasa, John Mazunda, and Mariam Kadzamira, 2016.

1497. Ghana's macroeconomic crisis: Causes, consequences, and policy responses. Stephen D. Younger, 2016.

1496. Temporary and permanent migrant selection: Theory and evidence of ability-search cost dynamics. Joyce J. Chen, Katrina Kosec, and Valerie Mueller, 2015.

1495. The effect of insurance enrollment on maternal and child healthcare use: The case of Ghana. Gissele Gajate-Garrido and Clement Ahiadeke, 2015.

1494. Stories of change in nutrition: A tool pool. Stuart Gillespie and Mara van den Bold, 2015.

1493. Optimal tariffs with smuggling: A spatial analysis of Nigerian rice policy options. Michael Johnson and Paul Dorosh, 2015.

1492. Smallholders and land tenure in Ghana: Aligning context, empirics, and policy. Isabel Lambrecht and Sarah Asare, 2015.

1491. Returns to agricultural public spending in Africa South of the Sahara. Samuel Benin, 2015.

1490. Lost in translation: The Fractured conversation about trade and food security. Eugenio Díaz-Bonilla, 2015.

1489. Gender roles and food safety in 20 informal livestock and fish value chains. Delia Grace, Kristina Roesel, Erastus Kang'ethe, Bassirou Bonfoh, and Sophie Theis, 2015.

1488. Farm household typologies and mechanization patterns in Nepal Terai: Descriptive analysis of the Nepal Living Standards Survey. Hiroyuki Takeshima, Rajendra Prasad Adhikari, Mahendra Nath Poudel, and Anjani Kumar, 2015.

1487. Public-private partnerships and the reduction of undernutrition in developing countries. John Hoddinott, Stuart Gillespie, and Sivan Yosef, 2015.

1486. How does women's time in reproductive work and agriculture affect maternal and child nutrition?: Evidence from Bangladesh, Cambodia, Ghana, Mozambique, and Nepal. Hitomi Komatsu, Hazel Jean L. Malapit, and Sophie Theis, 2015.

1485. US maize data reveals adaptation to heat and water stress. Timothy S. Thomas, 2015.

1484. Customary tenure and innovative measures of safeguarding land rights in Africa: The community land initiative (iniciativa de terras comunitárias) in Mozambique. Hosaena Ghebru, Raul Pitoro, and Sileshi Woldeyohannes, 2015. 


\section{INTERNATIONAL FOOD POLICY RESEARCH INSTITUTE}

\section{www.ifpri.org}

IFPRI HEADQUARTERS

2033 K Street, NW

Washington, DC 20006-1002 USA

Tel.: +1-202-862-5600

Fax: +1-202-467-4439

Email: ifpri@cgiar.org

IFPRI NEW DELHI

NASC, DPS Road, Opp Todapur, Pusa

New Delhi 110-012 India

Tel.: 9111 2584-6565

Fax: 9111 2584-8008 / 2584-6572

Email: ifpri-newdelhi@cgiar.org 